ORNL/CF-02/10

\title{
SEMI-ANNUAL TECHNICAL PROGRESS REPORT OF RADIOISOTOPE POWER SYSTEM MATERIALS PRODUCTION AND TECHNOLOGY PROGRAM TASKS FOR OCTOBER 1, 2001 THROUGH MARCH 31, 2002
}

\author{
Prepared for Department of Energy \\ Office of Space and Defense Power Systems \\ under Budget and Reporting Classification \\ AF 701020 0, AF 706000 0, and AF 7030000
}

by

Radioisotope Power System Program

Metals and Ceramics Division

Oak Ridge National Laboratory

Oak Ridge National Laboratory

Oak Ridge, Tennessee 37831-6080

operated by UT-Battelle, LLC

for the

U.S. Department of Energy

Contract DE-AC05-00OR22725 
This page intentionally blank 


\section{CONTENTS}

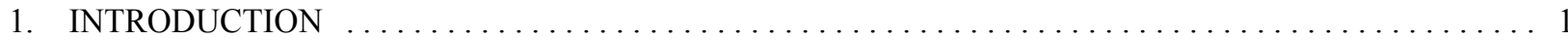

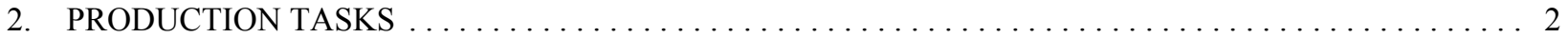

2.1 CARBON-BONDED CARBON FIBER $\ldots \ldots \ldots \ldots \ldots \ldots \ldots \ldots \ldots \ldots \ldots \ldots \ldots \ldots \ldots \ldots \ldots \ldots \ldots$

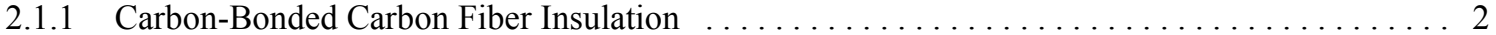

2.2 IRIDIUM-ALLOY BLANK AND FOIL PRODUCTION $\ldots \ldots \ldots \ldots \ldots \ldots \ldots \ldots \ldots \ldots \ldots$

2.2.1 Preparation of DOP-4 Iridium Alloy Foil $\ldots \ldots \ldots \ldots \ldots \ldots \ldots \ldots \ldots \ldots \ldots \ldots \ldots \ldots \ldots \ldots$

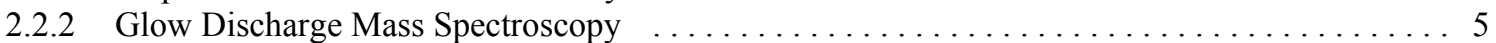

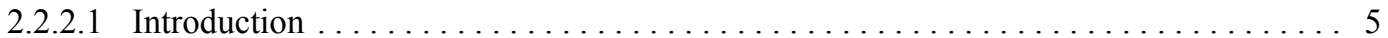

2.2.2.2 Quality Assurance Reference Materials $\ldots \ldots \ldots \ldots \ldots \ldots \ldots \ldots \ldots \ldots \ldots \ldots 5$

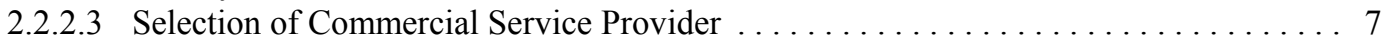

2.2.2.4 Analysis of ORNL Reference Materials . ..................... 7

2.2.2.5 Development of Analytical Procedure for Shiva Technologies $\ldots \ldots \ldots \ldots \ldots \ldots$

2.2.2.6 Comparison of Analyses Obtained by Shiva with Previous Analyses

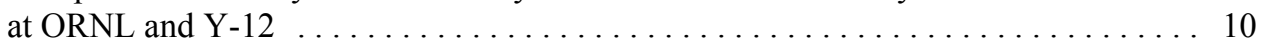

2.2.2.6.1 Bulk Analysis of Sheet and Blank Materials . . . . . . . . . . . . . . 10

2.2.2.6.2 "Surface" Analysis of Samples . . . . . . . . . . . . . . . . . . . . . 16

2.2.3.6.3 Analysis of Foil Materials ... . . . . . . . . . . . . . . . . . . . . 17

2.2.3.6.4 Analysis of Powder Materials ...................... 17

2.2.2.7 Quality Assurance System at Shiva Technologies . . . . . . . . . . . . . . . . . 24

2.2.2.7.1 Accreditation of Shiva by National and International Organizations . . . . 24

2.2.2.7.2 Detailed Description of Facilities . . . . . . . . . . . . . . . 25

2.2.2.7.3 Quality Assurance Program . . . . . . . . . . . . . . . . . . . . . . . . 25

2.2.2.7.4 Analysis Reports ............................... 25

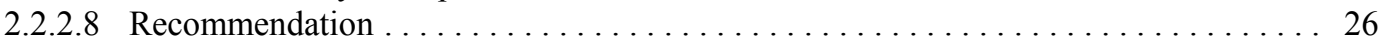

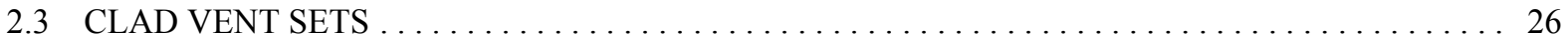

2.3.1 Completion and Shipment of 5 FQ CVS from FY $2001 \ldots \ldots \ldots \ldots \ldots \ldots \ldots \ldots \ldots \ldots \ldots \ldots \ldots \ldots \ldots$

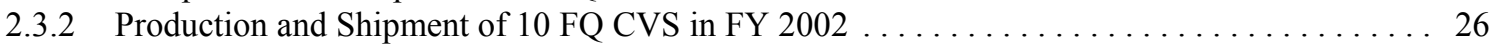

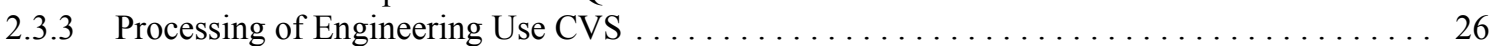

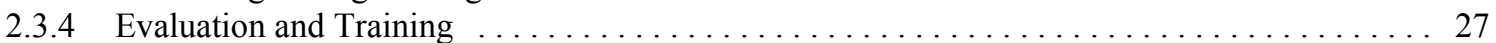

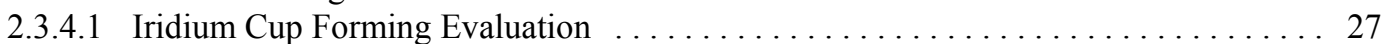

2.3.4.2 Frit Vent Backing and Cover Disc Fabrication Evaluation . . . . . . . . . . . . . 29

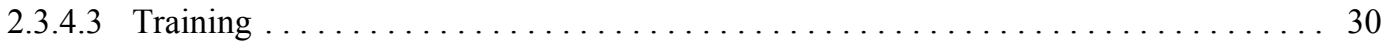

3. BASE TECHNOLOGY PROGRAM AND TECHNICAL SUPPORT ACTIVITIES $\ldots \ldots \ldots \ldots \ldots \ldots . . \ldots 1$

3.1 TECHNICAL SUPPORT FOR THE ARPS AMTEC CELL DEVELOPMENT $\ldots \ldots \ldots \ldots \ldots \ldots$.

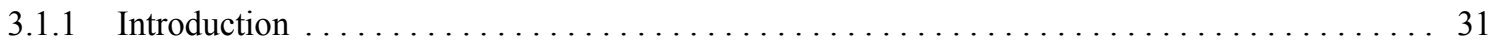

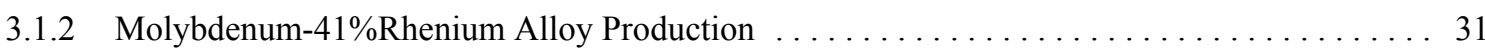

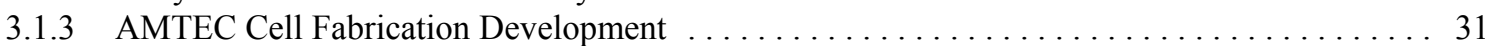

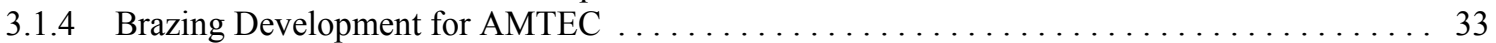

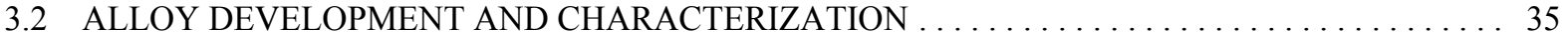

3.2.1 Impact Properties of DOP-26 Iridium Doped with $15-50 \mathrm{wppm} \mathrm{Si} \ldots \ldots \ldots \ldots \ldots \ldots \ldots$

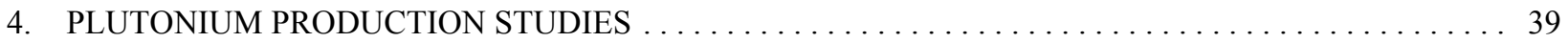

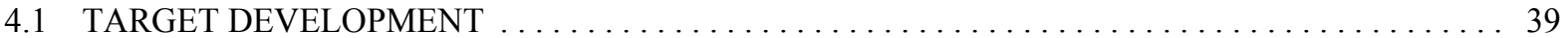

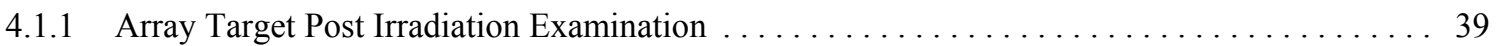

4.1.2 ATR Production Calculations . . . . . . . . . . . . . . . . . . . . . . . . . . . . . 39

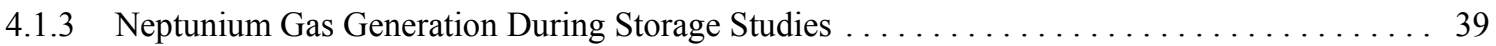

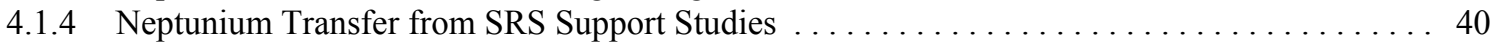


This page intentionally left blank 


\section{INTRODUCTION}

The Office of Space and Defense Power Systems of the Department of Energy (DOE) provides Radioisotope Power Systems (RPS) for applications where conventional power systems are not feasible. For example, radioisotope thermoelectric generators were supplied by the DOE to the National Aeronautics and Space Administration for deep space missions including the Cassini Mission launched in October of 1997 to study the planet Saturn. The Oak Ridge National Laboratory (ORNL) has been involved in developing materials and technology and producing components for the DOE for more than three decades. For the Cassini Mission, for example, ORNL was involved in the production of carbon-bonded carbon fiber (CBCF) insulator sets, iridium alloy blanks and foil, and clad vent sets (CVS).

This report has been divided into three sections to reflect program guidance from the Office of Space and Defense Power Systems for fiscal year (FY) 2002. The first section deals primarily with maintenance of the capability to produce flight quality (FQ) CBCF insulator sets, iridium alloy blanks and foil, and CVS. In all three cases, production maintenance is assured by the manufacture of limited quantities of FQ components. The second section deals with several technology activities to improve the manufacturing processes, characterize materials, or to develop technologies for new radioisotope power systems. The last section is dedicated to studies related to the production of ${ }^{238} \mathrm{Pu}$. 


\section{PRODUCTION TASKS}

\subsection{CARBON-BONDED CARBON FIBER}

The goal of this effort is to maintain production capability for CBCF insulation sets. These are produced under closely controlled conditions and stringent quality assurance procedures to ensure compliance with material specifications at each step in the production process, from the handling of raw materials to finished parts. Dedicated facilities for CBCF production remain in the Carbon and Insulation Materials Technology Laboratory. Periodic exercise of production activities is performed to assure that the processes can be successfully executed and to verify personnel competencies and adequacy of training, equipment, and procedures. In the first quarter the program underwent a quality assurance review. A significant quantity of legacy $\mathrm{CBCF}$ materials and unqualified insulators were reviewed and dispositioned.

Our goals this year include the following: (1) Complete the characterization of 18 CBCF sleeves from FY 2000 production runs. (2) Complete the qualification of five CBCF sleeves and disks from FY 2001 production runs. (3) Produce and certify five new sets of CBCF sleeves and disks. (4) Take measures to enhance the reserve of critical raw materials.

The principal focus in the first half of FY 2002 has been on issues related to qualifying CBCF insulators. Physical Properties User Center Procedure MET-CER-TS-50, Rev. 1, "Determination of Thermal Conductivity of CBCF Insulation at Room Temperature in Vacuum" was revised and approved for use. The revised procedure allows for the use of a new instrument for the determination of thermal conductivity. The new instrument is limited to a best vacuum of around $8 \times 10^{-5}$ torr. The revised procedure requires a vacuum of $<10^{-4}$ torr and broadens the allowable temperature range "3/C (15/C to 27/C) to be inclusive of more typical ambient laboratory conditions.

\section{Effect of Pressure:}

Thermal conductivity was determined for CBCF samples taken from sleeve production runs E-6, E-7, and E-8, as well as disk production run F-4. Thermal diffusivity was measured at room temperature and at pressure levels including 8 $\mathrm{X} 10^{-5}$ torr, $9 \times 10^{-5}$ torr, $2 \times 10^{-2}$ torr, 0.5 torr and 1 torr. The results presented in the figure below illustrate that the thermal diffusivity of $\mathrm{CBCF}$ is independent of pressure below $10^{-2}$ torr. This behavior can be attributed to a lack of significant energy transfer by gas molecules at low pressures. The mean free path, $\lambda$, of a gas molecule according to kinetic theory is ${ }^{1}$

$$
\lambda=1 /\left(\mathrm{s} 2 \mathrm{H} \pi \mathrm{Hd}_{\mathrm{o}}^{2} \mathrm{Hn}\right)
$$

Where $\mathrm{d}_{\mathrm{o}}$ is the molecular diameter and $\mathrm{n}$ is the gas density. The mean free path is clearly pressure dependent. For air at room temperature, the mean free path is $\lambda(\mathrm{mm})=6.6 / \mathrm{P}$ where $\lambda$ has units of millimeters and $\mathrm{P}$ is pressure in Pascal. Calculated values of mean free path are given in Table 1 for pressures relevant to the current discussion. There is a marked increase in thermal diffusivity around $\lambda$ equal to the specimen thickness $(1 \mathrm{~mm})$ as can be seen in the plot. The inter-fiber void dimensions in CBCF are on the order of $0.01 \mathrm{~mm}$. This insensitivity to gas pressure at room temperature is typically observed in materials of this type and in powders when the gas mean free path approaches the size of the voids. The critical dimension for $\mathrm{CBCF}$ is the specimen thickness since the material is $90 \%$ free space.

\section{Effect of Temperature:}

The temperature range allowed for room temperature measurement of thermal diffusivity has been expanded by " 3/C. The maximum temperature sensitivity of the thermal conductivity of CBCF near room temperature is about 0.0002 $\mathrm{W} / \mathrm{mK}^{2}$. Thus, a temperature change of $3 / \mathrm{C}$ would change the determination of thermal conductivity by only 0.0006 $\mathrm{W} / \mathrm{mK}$. Since results are reported to two significant figures, the maximum effect of the higher/lower temperature on the reported data would be $0.001 \mathrm{~W} / \mathrm{mK}$. This insensitivity to temperature over this range is typically observed in materials of this type and in powders when the measurement temperature is low enough that radiation transport across voids has not become significant.

\footnotetext{
${ }^{1}$ J.F. O’Hanlon, “A user’s Guide to Vacuum Technology”, John Wiley \& Sons, Inc. (1980).
} 


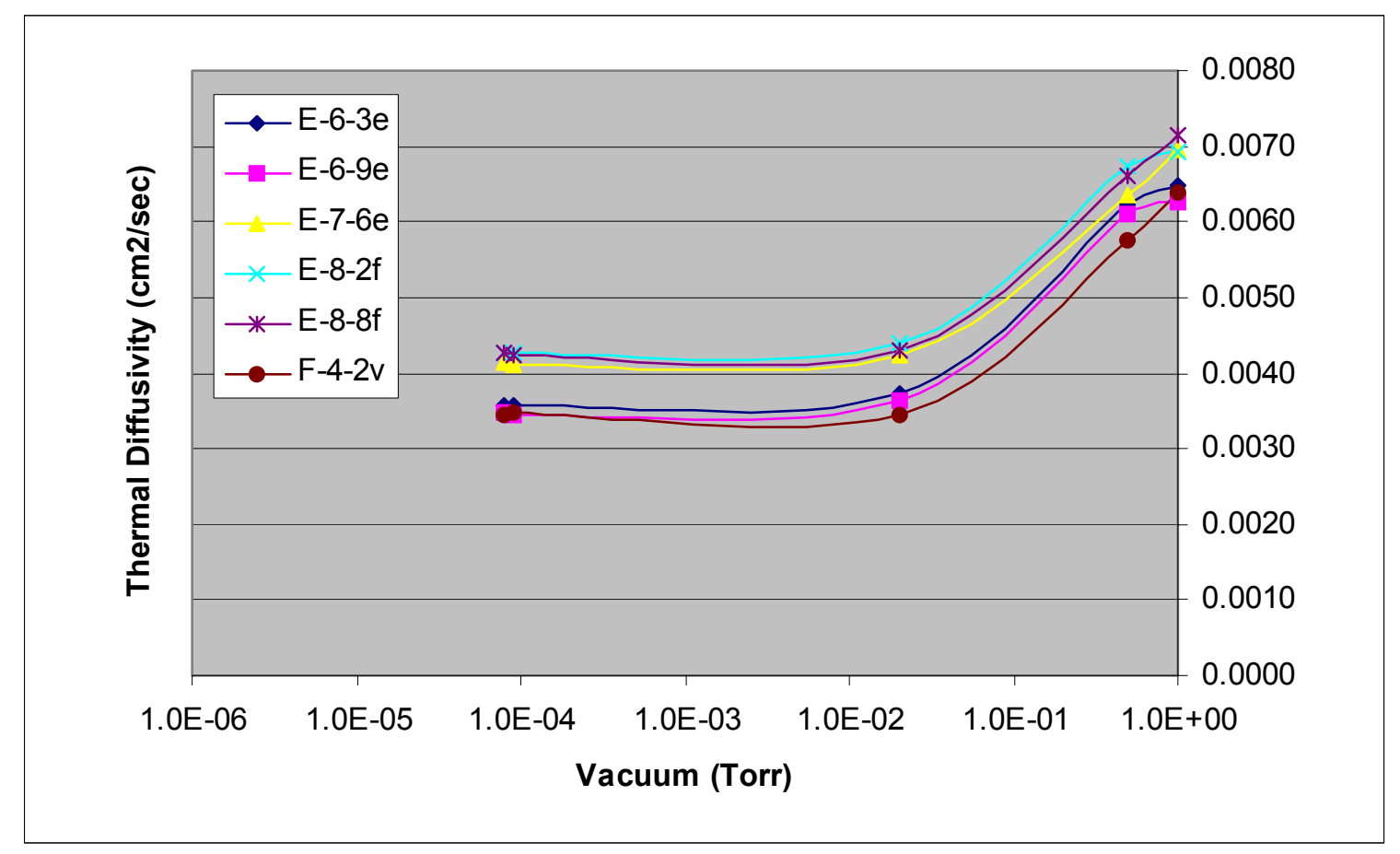

Table 1. Effect of Pressure on Mean Free Path and Thermal Diffusivity

\begin{tabular}{|c|c|c|c|}
\hline $\begin{array}{c}\text { Pressure } \\
\text { (torr) }\end{array}$ & $\begin{array}{c}\text { Pressure } \\
(\text { Pascal })\end{array}$ & $\begin{array}{c}\text { Mean Free Path } \\
(\mathrm{mm})\end{array}$ & $\begin{array}{c}\text { Thermal Diffusivity* } \\
\left(\mathrm{cm}^{2} / \mathrm{s}\right)\end{array}$ \\
\hline $10^{-5}$ & $1.33 \times 10^{-3}$ & 4950 & ---- \\
\hline $8 \times 10^{-5}$ & $1.07 \times 10^{-2}$ & 563 & 0.0043 \\
\hline $9 \times 10^{-5}$ & $1.20 \times 10^{-2}$ & 550 & 0.0043 \\
\hline $2 \times 10^{-2}$ & 2.67 & 2.25 & 0.0044 \\
\hline .5 & 66.7 & $9 \times 10^{-2}$ & 0.0067 \\
\hline 1 & 133 & $4.5 \times 10^{-2}$ & 0.0069 \\
\hline
\end{tabular}

*Specimen E-8-2

The average thermal conductivity determined for E- 7 and E-8 sleeve samples was $0.059 \mathrm{~W} / \mathrm{mK}$ with a standard deviation of $0.004 \mathrm{~W} / \mathrm{mK}$. The variability of this property measurement expressed in terms of standard deviation incorporates both the inhomogeniety of the $\mathrm{CBCF}$ as well as the precision limits of the instrumentation. The maximum effect of a $3 / \mathrm{C}$ temperature variation is only $15 \%$ of the standard deviation expected in typical measurements. Furthermore, typical thermal conductivity values determined for $\mathrm{CBCF}$ are less than $0.063 \mathrm{~W} / \mathrm{mK}$, well below the allowable maximum of $0.086 \mathrm{~W} / \mathrm{mK}$. The broader temperature range allowed for room temperature thermal diffusivity measurements will not affect the suitability of $\mathrm{CBCF}$ for service. With the approved thermal conductivity procedure in place, testing and qualification of CBCF sleeves from FY 2000 production runs was completed.

A high vacuum furnace, shown in Figure 1, used for outgassing test specimens for qualification of CBCF was completely rebuilt. The first specimens to be outgassed will be those from FY 2001 production runs. With the completion of the outgassing furnace and the recent revisions and approvals of the sulfur analysis procedure and the thermal conductivity procedure, qualification of $\mathrm{CBCF}$ can now proceed. 

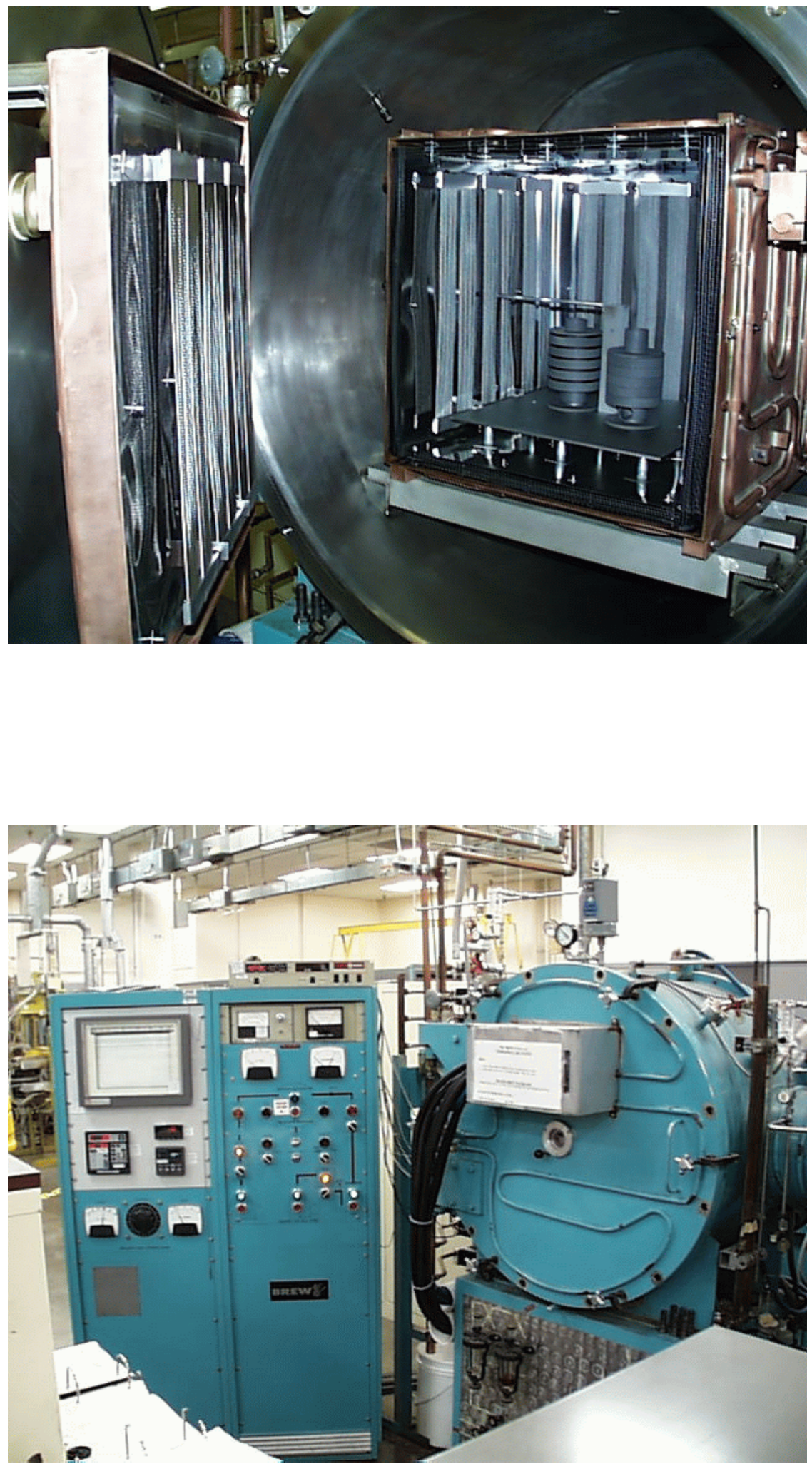

Fig. 1. Rebuilt high vacuum furnace for outgassing CBCF specimens. 
The goals for this activity are to produce flight-quality blanks and foil under full configuration control and to supply materials needed for clad vent set demonstration and maintenance activities. During the first half of FY 2002 six drop cast ingots of DOP-4 iridium alloy were prepared and rolled to foil. A procedure for glow discharge analysis of iridium materials was prepared, together with a deviation request and detailed technical justification, and submitted to the ORNL CCB for approval.

\subsubsection{Preparation of DOP-4 Iridium Alloy Foil}

Six drop-cast iridium alloy ingots of $19-\mathrm{mm}$ square by 50 -cm high were prepared by arc-melting. The ingots, identified as GFR231 through GFR236, were prepared from starting materials consisting of equal quantities of electron-beam melted buttons of Ir- $0.3 \% \mathrm{~W}$ from the G-18 blended powder batch and recycle DOP-26 alloy from ingot ER 10 . The drop castings were homogenized, assembled into molybdenum frames and hot rolled with molybdenum covers to a thickness of $0.7-\mathrm{mm}$. The sheets were trimmed, cleaned, recrystallized and warm-rolled to a thickness of $0.2-\mathrm{mm}$. The foils were again cleaned and cold-rolled to final thicknesses of $0.125 \mathrm{~mm}$. A total of sixty pieces of foil with a final weight of $1.5 \mathrm{~kg}$ were produced. Sampling and cleaning of the foils were initiated. The foil should yield 0.5 square meters of finished product.

\subsubsection{Glow Discharge Mass Spectroscopy}

\subsubsection{Introduction}

Accurate chemical analyses are required for raw materials, intermediate products and the clad vent set products manufactured at the Oak Ridge National Laboratory (ORNL). Chemical analysis is currently performed at the Oak Ridge Y-12 Plant (Y-12) under procedure GPHS-Y-024. The Kratos glow discharge mass spectrometer (GDMS) has been used at Y-12 for the analysis of iridium materials since 1994. Prior to that time a spark source mass spectrometer was used. The glow discharge technique provides improved repeatability and sensitivity and avoids the subjectivity and much of the operator dependence associated with the spark source method. However, the future availability of the Kratos instrument for analysis of iridium materials is uncertain. In 1999 a VG9000 mass spectrometer at ORNL was qualified for analysis of iridium alloy materials under Deviation Request No. Ir - 199 using ORNL procedure CASDAM-TRL-0002, "Elemental Analysis of Iridium and its Alloys by Glow Discharge Mass Spectrometry. Due to personnel changes it is no longer practical to maintain the availability of this instrument for analysis of iridium alloys. This section describes the methods used to qualify an outside provider of GDMS services for analysis of iridium alloy materials. It includes results of analyses performed by Shiva Technologies using drafts of the analytical procedure MET-MatP-SOP-79, "Elemental Analysis of Iridium and Iridium Alloys by Glow Discharge Mass Spectrometry". These analyses include samples of materials previously analyzed both at Y-12 and ORNL.

\subsubsection{Quality Assurance Reference Materials}

Quality assurance reference (QAR) materials are batches of iridium samples which are well characterized with respect to chemistry and which are used on a routine basis to assure that the mass spectroscope is operating properly and is producing consistent data over time. The QAR is run with each group of analytical samples and the results of the QAR material analysis is compared to that obtained for previous runs of the same material. This material should be as homogeneous as possible and contain alloying elements at appropriate levels and also contain all impurity elements of interest at levels of some significant fraction of the specified maximum. Two iridium sheet sections were selected for use as QAR materials, one labeled as G1-10 and the other labeled RS10-9-1. The homogeneity of these materials was previously quantified using the VG9000 GDMS at ORNL. The relative variation in each element for the runs is shown in Table 1 . The relative standard deviation, i.e. the standard deviation divided by the average value, is typically $5 \%$. The average contents to which the relative standard deviations apply are shown in Table 2 . The only values greater than $11 \%$ are associated with average elemental impurity contents of $5 \mathrm{ppm}$ or less. 
The QAR materials were judged to be adequate in homogeneity for use with the procedure. The RS10-9-1 material contains higher levels of most impurity elements and is better suited to assure consistent impurity analyses, while the G1-10 material is better characterized with respect to the alloying elements, W, Th, and Al. Therefore, both QAR materials are used. The compositions of the QAR materials using the relative sensitivity factor (RSF) values described in the attachment to DR-Ir-199 are listed in Table 2. The standard deviation $(\sigma)$ in analysis of the alloying elements, $\mathrm{Al}, \mathrm{W}$, and Th are shown in Table 3 with upper and lower limits of $\pm 3 \sigma$ from the mean shown in Table 2 .

Table 1. Reproducibility of QAR materials G1-10 and RS10-9-1

\begin{tabular}{|c|c|c|}
\hline Element & $\frac{\text { Relative Std. Dev. }}{\text { in G1-10,\% }}$ & $\frac{\text { Relative Std. Dev. }}{\text { in RS10-9-1.\% }}$ \\
\hline
\end{tabular}

$\begin{array}{ccc}\mathrm{Al} & 3 & 8 \\ \mathrm{Si} & 4 & 12 \\ \mathrm{Ti} & 6 & 3 \\ \mathrm{Cr} & 10 & 5 \\ \mathrm{Fe} & 10 & 5 \\ \mathrm{Ni} & 25 & 11 \\ \mathrm{Cu} & 17 & 28 \\ \mathrm{Nb} & 10 & 3 \\ \mathrm{Mo} & 3 & 5 \\ \mathrm{Ru} & 3 & 5 \\ \mathrm{Ta} & 14 & 5 \\ \mathrm{~W} & 4 & 3 \\ \mathrm{Pt} & 6 & 6 \\ \mathrm{Th} & 3 & 3\end{array}$

Table 2. Average Compositions of Quality Assurance Reference Materials, ppm by Weight

\begin{tabular}{|c|c|c|c|c|}
\hline No. & $\underline{\text { Name }}$ & $\frac{\text { Specification }}{\underline{\text { (blanks) }}}$ & $\underline{\mathrm{G} 1-10}$ & $\underline{\mathrm{RS} 10-9-1}$ \\
\hline 13 & $\mathrm{Al}$ & $20-80$ & 50 & 53 \\
\hline 14 & $\mathrm{Si}$ & 50 & 1.8 & 3.4 \\
\hline 22 & $\mathrm{Ti}$ & 50 & 1.9 & 3.5 \\
\hline 24 & $\mathrm{Cr}$ & 50 & 0.2 & 5.7 \\
\hline 26 & $\mathrm{Fe}$ & 200 & 0.8 & 22 \\
\hline 28 & $\mathrm{Ni}$ & 50 & 0.1 & 4.1 \\
\hline 29 & $\mathrm{Cu}$ & 50 & 0.4 & 0.7 \\
\hline 40 & $\mathrm{Zr}$ & 50 & 0.3 & $<0.5$ \\
\hline 41 & $\mathrm{Nb}$ & 50 & 0.3 & 37 \\
\hline 42 & Mo & 50 & 1.0 & 27 \\
\hline 44 & $\mathrm{Ru}$ & 50 & 17 & 17 \\
\hline 45 & $\mathrm{Rh}$ & 150 & 3.0 & 3.8 \\
\hline 73 & $\mathrm{Hf}$ & 50 & $<0.5$ & 2.2 \\
\hline 74 & $\mathrm{Ta}$ & 50 & 2.7 & 7.1 \\
\hline 75 & W & $2000-4000$ & 3000 & 3230 \\
\hline 76 & $\mathrm{Re}$ & 50 & $<0.5$ & 1.7 \\
\hline 77 & Os & 50 & $<0.5$ & 1.1 \\
\hline 78 & $\mathrm{Pt}$ & 50 & 3.5 & 3.0 \\
\hline 90 & Th & $30-90$ & 60 & 55 \\
\hline
\end{tabular}


Table 3. Standard Deviations in Composition and Upper and Lower Limits of Quality Assurance Reference Materials, ppm by Weight

\begin{tabular}{|c|c|c|c|c|c|c|}
\hline & \multicolumn{3}{|c|}{ G1-10 } & \multicolumn{3}{|c|}{ RS10-9 -1 } \\
\hline & $\underline{\mathrm{Al}}$ & $\underline{\mathrm{W}}$ & $\underline{\mathrm{Th}}$ & $\underline{\mathrm{Al}}$ & $\underline{\mathrm{W}}$ & $\underline{T h}$ \\
\hline Mean & $\overline{50}$ & $3 \overline{000}$ & $\overline{60.0}$ & $\overline{53}$ & $3 \overline{23} 0$ & $\overline{55.0}$ \\
\hline Std. Dev. $(\sigma)$ & 1.7 & 123 & 1.8 & 4.0 & 99 & 1.9 \\
\hline Mean $+3 \sigma$ & 55 & 3369 & 65.4 & 65 & 3527 & 60.7 \\
\hline Mean - $3 \sigma$ & 45 & 2631 & 54.6 & 41 & 2933 & 49.3 \\
\hline
\end{tabular}

\subsubsection{Selection of Commercial Service Provider}

Two potential outside service providers, Shiva Technologies, Inc., Syracuse NY (Shiva) and Engelhard, Carteret NJ, were chosen for initial evaluation based on their previous experience in analysis of iridium materials. Samples of iridium alloy reference materials G1-10 and RS10-9-1 were submitted to both service providers without any information on the compositions. Evaluation of the results from Shiva indicated that the analyses for all elements are almost invariably within a factor of two of the values determined by ORNL. The results of the analyses for individual elements obtained from the same reference material at different times also varied by as much as a factor of two. The variation was considered acceptable for an analysis not corrected using standards. The results of uncorrected analyses from Engelhard showed agreement to within a factor of two for most elements but with some much larger discrepancies for aluminum and several important impurity elements. Shiva was selected for further evaluation on the basis of these results. This section provides detailed information to qualify Shiva for analysis of iridium alloy materials for the RPS program.

\subsubsection{Analysis of ORNL Reference Materials}

Samples of the two reference iridium alloy materials were provided to Shiva in July 2000 and again in December 2000. The results reported by Shiva are listed in Tables 4 and 5 for the RS10-9 and G1-10 materials, respectively. The variation is considered acceptable for an analysis not corrected using standards. The data was analyzed using a method of correction equivalent to that in the existing procedure for iridium alloy analysis at ORNL. The composition of the alloying elements in the RS10-9 material was corrected using the G1-10 reference material analyzed on the same day. The composition of important impurity elements in the G1-10 materials was corrected using the RS10-9 reference material analyzed on the same day. The corrected Shiva analyses for alloying elements in the RS10-9 material shown in Table 6 are in good agreement with the reference values. The corrected analyses for impurity elements in the G-1-10 material, shown in Table 7, are in good agreement with the reference values. The differences between values for the Shiva and the reference values are equivalent to $10 \%$ of the specification range or less, and this is acceptable. 
Table. 4 Comparison of Uncorrected Analysis from Shiva to ORNL Reference Values for RS-10-9

\begin{tabular}{|c|c|c|c|c|}
\hline Element & Specification* & $\frac{\text { ORNL }}{\text { reference }}$ & $\frac{\text { Shiva }}{\text { Julv } 2000}$ & $\stackrel{\text { Shiva }}{\text { December } 2000}$ \\
\hline $\mathrm{Al}$ & $20-80$ & 53 & 50 & 65 \\
\hline $\mathrm{Si}$ & 50 & 3.4 & 5 & 8.1 \\
\hline $\mathrm{Ti}$ & 50 & 3.5 & 2.3 & 2.4 \\
\hline $\mathrm{Cr}$ & 50 & 5.7 & 8.8 & 19 \\
\hline $\mathrm{Fe}$ & 200 & 22 & 20 & 33 \\
\hline $\mathrm{Ni}$ & 50 & 4.1 & 2.9 & 4.8 \\
\hline $\mathrm{Cu}$ & 50 & 0.7 & 0.9 & 1.9 \\
\hline $\mathrm{Zr}$ & 50 & $<0.5$ & 1 & 1.2 \\
\hline $\mathrm{Nb}$ & 50 & 37 & 34 & 35 \\
\hline Mo & 50 & 27 & 27 & 37 \\
\hline $\mathrm{Ru}$ & 50 & 17 & 14 & 16 \\
\hline $\mathrm{Rh}$ & 150 & 3.8 & 3.5 & 5.1 \\
\hline $\mathrm{Hf}$ & 50 & 2.2 & 0.5 & 0.55 \\
\hline W & $2000-4000$ & 3230 & 3400 & 4000 \\
\hline $\operatorname{Re}$ & 50 & 1.7 & 1.9 & 2.2 \\
\hline Os & 50 & 1.1 & 0.7 & 1.0 \\
\hline $\mathrm{Pt}$ & 50 & 3 & 2.9 & 2.7 \\
\hline Th & $30-90$ & 55 & 40 & 37 \\
\hline
\end{tabular}

*Specification range for alloying elements and maximum value for impurity elements

Several minor impurity elements, with concentrations in the range of 0.1 to $1 \mathrm{ppm}$, for which corrections to reference values are not possible are listed in Table 8 with analyzed contents from ORNL and Shiva. Again the agreement is quite good.

\subsubsection{Development of Analytical Procedure for Shiva Technologies}

The procedure MET-MatP-SOP-79 was developed working closely with Shiva using the ORNL procedure CASD-AMTRL-0002 as a starting point. There are three notable technical differences between the two procedures. The most important is that the RSF values are not included in procedure MET-MatP-SOP-79, since the values used by Shiva are considered proprietary. The control of process results is instead achieved with the use of reference materials with each analysis or group of analyses. This a better method of control. The two reference materials G1-10 and RS10-9 are used to obtain corrected concentration values for the 3 alloying elements and 16 important impurity elements. The effect of using these reference materials is that for these 19 elements the particular RSF value used has no effect on the corrected analytical value. The other impurity elements do require use of a particular RSF value. The procedure MET-MatPSOP-79 requires that no change be made in any RSF value used for the iridium alloy samples without prior notification of program personnel. The methods by which the RSF values are controlled are described in the section on quality assurance at Shiva below. The use of the reference materials with each group of samples also provides a qualitative check on those elements that are not reported with corrected values. Any major change in RSF values or equipment operating conditions would be seen as a change in the minor impurity analysis of the reference materials. A second technical difference in the procedures is the preparation and analysis of powder samples. The previous procedure used at ORNL involves pressing powder on to a pure gold pin. The MET-MatP-SOP-79 procedure uses a high purity indium powder as a binder. This is acceptable because the analysis for indium is obtained using a second sample in a metal holder. 
Table. 5 Comparison of Uncorrected Analysis from Shiva to ORNL Reference Values for G1-10

\begin{tabular}{|c|c|c|c|c|}
\hline Element & Specification* & $\frac{\text { ORNL }}{\text { reference }}$ & $\frac{\text { Shiva }}{\text { July } 2000}$ & $\stackrel{\text { Shiva }}{\text { December } 2000}$ \\
\hline$\overline{\mathrm{Al}}$ & 100 & 50 & 45 & 63 \\
\hline $\mathrm{Si}$ & 50 & 1.8 & 3 & 3.6 \\
\hline $\mathrm{Ti}$ & 50 & 1.9 & 1 & 1.3 \\
\hline $\mathrm{Cr}$ & 50 & 0.2 & 0.35 & 0.56 \\
\hline $\mathrm{Fe}$ & 200 & 0.8 & 0.75 & 0.93 \\
\hline $\mathrm{Ni}$ & 50 & 0.1 & 0.13 & 0.15 \\
\hline $\mathrm{Cu}$ & 50 & 0.4 & 0.5 & 0.77 \\
\hline $\mathrm{Zr}$ & 50 & 0.3 & 0.35 & 0.34 \\
\hline $\mathrm{Nb}$ & 50 & 0.3 & 0.2 & 0.24 \\
\hline Mo & 50 & 1 & 0.9 & 1.2 \\
\hline $\mathrm{Ru}$ & 50 & 17 & 12 & 15 \\
\hline $\mathrm{Rh}$ & 150 & 3 & 3 & 4.2 \\
\hline $\mathrm{Hf}$ & 50 & $<0.5$ & $<0.01$ & $<0.01$ \\
\hline $\mathrm{W}$ & $2000-4000$ & 3000 & 3200 & 3700 \\
\hline $\operatorname{Re}$ & 50 & $<0.5$ & 0.08 & 0.06 \\
\hline Os & 50 & $<0.5$ & 0.3 & $<0.2$ \\
\hline $\mathrm{Pt}$ & 50 & 3.5 & 3.1 & 2.8 \\
\hline Th & $30-90$ & 60 & 41 & 36 \\
\hline
\end{tabular}

*Specification range for alloying elements and maximum value for impurity elements

Table. 6 Comparison of Corrected Analysis For Shiva Results of Alloying Elements in RS-10-9 Reference Material

\begin{tabular}{|c|c|c|c|}
\hline \multirow[b]{3}{*}{ Element } & \multicolumn{2}{|c|}{ Content, ppm by Weigh } & \multirow[b]{2}{*}{ Shiva } \\
\hline & ORNL & Shiva & \\
\hline & Reference & July 2000 & December \\
\hline$\overline{\mathrm{Al}}$ & 53 & 56 & 52 \\
\hline W & 3230 & 3190 & 3240 \\
\hline Th & 55 & 59 & 62 \\
\hline
\end{tabular}

Table. 7 Comparison of Corrected Analysis For Shiva Results of Impurity Elements in G1-10 Reference Material

\begin{tabular}{|c|c|c|c|}
\hline \multicolumn{4}{|c|}{ Content, ppm by Weight } \\
\hline & $\underline{\text { ORNL }}$ & Shiva & Shiva \\
\hline Element & $\underline{\text { Reference }}$ & July 2000 & December 2000 \\
\hline $\mathrm{Si}$ & 1.8 & 2.0 & 1.5 \\
\hline $\mathrm{Ti}$ & 1.9 & 1.5 & 1.9 \\
\hline $\mathrm{Cr}$ & 0.2 & 0.2 & 0.2 \\
\hline $\mathrm{Fe}$ & 0.8 & 0.8 & 0.6 \\
\hline $\mathrm{Ni}$ & 0.1 & 0.2 & 0.1 \\
\hline $\mathrm{Cu}$ & 0.4 & 0.4 & 0.3 \\
\hline $\mathrm{Nb}$ & 0.3 & 0.2 & 0.3 \\
\hline Mo & 1.0 & 0.9 & 0.9 \\
\hline $\mathrm{Ru}$ & 17 & 14.6 & 15.9 \\
\hline $\mathrm{Rh}$ & 3 & 3.3 & 3.1 \\
\hline $\operatorname{Re}$ & $<0.5$ & 0.1 & 0.0 \\
\hline Os & $<0.5$ & 0.5 & 0.2 \\
\hline $\mathrm{Pt}$ & 3.5 & 3.2 & 3.1 \\
\hline
\end{tabular}


Table. 8 Comparison of Minor Impurity $(<1 \mathrm{ppm})$ Analyses Made Without Correction for Standard

\begin{tabular}{|c|c|c|c|c|}
\hline & \multicolumn{2}{|c|}{$\frac{\text { G1-10 ppm by }}{\underline{\text { weight }}}$} & \multicolumn{2}{|c|}{$\underline{\mathrm{RS} 10-9 \mathrm{ppm} \text { by weight }}$} \\
\hline & $\underline{\text { ORNL }}$ & Shiva & ORNL & Shiva \\
\hline V & 0.05 & 0.06 & 0.2 & 0.33 \\
\hline $\mathrm{Mn}$ & 0.02 & 0.02 & 0.2 & 0.23 \\
\hline Co & 0.006 & 0.007 & 0.12 & 0.13 \\
\hline $\mathrm{Y}$ & 0.06 & 0.04 & 0.05 & 0.04 \\
\hline
\end{tabular}

The third technical difference is the "surface analysis" method. The purpose of this is to analyze a subsurface region averaging about 4 to $6 \mu \mathrm{m}$ beneath the sample surface. This is achieved by measuring the average sputtering rate of the surface during the sample analysis and acquiring and analyzing data from a sample pin early during the time of sputtering. Shiva determined that it was not possible to obtain data of good quality for all elements in the sampling time available. ORNL agreed to require that data be acquired and analyzed only for those 11 elements called for by specification GPHS-M-185 during the "surface" analysis portion of the data acquisition.

Bulk analysis of sheet samples were performed using various drafts of procedure MET-MatP-SOP-79 at three different times over a period of 10 months. The first group of samples was analyzed in May 2001 using the initial draft of the procedure. The results for a few of the samples analyzed at that time showed high levels of tantalum which was attributed to ion discharge from the standard tantalum specimen holder used by Shiva. An iridium alloy sample holder was fabricated and used for all subsequent analyses. This was incorporated into a second draft procedure dated October 31,2001 which also included more detailed instructions on the surface analysis method. The final draft of February 25, 2002 included the use of a single foil specimen rather than the stacked specimens used in earlier analyses and limited the number of elements included in the surface analysis in order to meet the time restrictions on data acquisition. All data reported here that was generated using earlier draft versions of the procedure is considered to be technically consistent with the methods of the final draft procedure.

\subsubsection{Comparison of Analyses Obtained by Shiva with Previous Analyses at ORNL and Y-12}

\subsection{Bulk Analysis of Sheet and Blank Materials}

The GDMS results of bulk analysis at ORNL, Y-12, and Shiva are shown in Tables 9 through 12 for sheet materials ER10-6, G2, MS1-1, and AR2-5 respectively. The date of each of the analyses by Shiva is shown. The specification limits for iridium alloy blanks are also shown for each element. The values are in weight ppm after correction using the two iridium alloy reference materials as described in procedure MET-MatP-SOP-79. Elements not listed in these Tables were not detectable in the ORNL or Shiva analyses. 
Table 9. Comparison of GDMS Bulk Analyses of ER10-6 Sheet Materials at ORNL, Y-12, and Shiva

\begin{tabular}{|c|c|c|c|c|c|}
\hline \multirow[b]{2}{*}{ Element } & \multirow[b]{2}{*}{$\underline{\text { Specification }}^{\mathrm{a}}$} & \multicolumn{4}{|c|}{ Chemical composition, ppm by wt } \\
\hline & & $\underline{\mathrm{Y}-12}$ & ORNL & $\underline{\text { Shiva }}^{\mathrm{b}}$ & $\underline{\text { Shiva }}^{\mathrm{c}}$ \\
\hline B & 50 & $<2$ & $<0.5$ & 0.05 & 0.05 \\
\hline $\mathrm{Na}$ & 50 & $<2$ & $<0.5$ & 0.08 & 0.1 \\
\hline $\mathrm{Mg}$ & 50 & $<2$ & $<0.5$ & 0.02 & $<0.01$ \\
\hline $\mathrm{Al}$ & $20-80$ & 62 & 54 & 54 & 48 \\
\hline $\mathrm{Si}$ & 50 & 4 & 3.2 & 3.4 & 3.9 \\
\hline $\mathrm{S}$ & 50 & $<2$ & $<0.5$ & 0.06 & $<0.01$ \\
\hline $\mathrm{Ti}$ & 50 & $<2$ & 3 & 3.4 & 3.7 \\
\hline V & 50 & $<2$ & $<0.5$ & 0.18 & 0.26 \\
\hline $\mathrm{Cr}$ & 25 & $<2$ & 2.5 & 3.2 & 2 \\
\hline $\mathrm{Mn}$ & 50 & $<2$ & $<0.5$ & 0.07 & 0.1 \\
\hline $\mathrm{Fe}$ & 150 & 5 & 11.2 & 12 & 8.4 \\
\hline Co & 50 & $<2$ & $<0.5$ & 0.04 & 0.06 \\
\hline $\mathrm{Ni}$ & 50 & $<5$ & 2.9 & 3 & 2.3 \\
\hline $\mathrm{Cu}$ & 50 & $<5$ & 1 & 0.8 & 0.55 \\
\hline $\mathrm{Zn}$ & 50 & $<5$ & $<0.5$ & 0.29 & 0.36 \\
\hline $\mathrm{Y}$ & 50 & $<2$ & $<0.5$ & 0.16 & 0.2 \\
\hline $\mathrm{Zr}$ & 50 & $<2$ & 0.3 & 0.37 & 0.5 \\
\hline $\mathrm{Nb}$ & 50 & $<2$ & 2.7 & 2.4 & 2.1 \\
\hline Mo & 50 & $<2$ & 16 & 18 & 15 \\
\hline $\mathrm{Ru}$ & 50 & 8 & 28 & 29 & 28 \\
\hline $\mathrm{Rh}$ & 150 & $<2$ & $<0.5$ & 8.3 & 8 \\
\hline $\mathrm{Pd}$ & 50 & $<5$ & $<0.5$ & $<0.01$ & 0.01 \\
\hline In & 50 & $<2$ & $<0.5$ & 0.09 & 0.07 \\
\hline $\mathrm{Hf}$ & 50 & $<2$ & 1.7 & 1.6 & 1.7 \\
\hline Тa & 50 & $<2$ & 1.5 & 9.2 & 1.4 \\
\hline W & $2000-4000$ & 3190 & 3120 & 3230 & 3260 \\
\hline $\mathrm{Re}$ & 50 & $<2$ & 1.3 & 1.1 & 1.2 \\
\hline Os & 50 & $<2$ & 0.3 & $<0.2$ & $<0.2$ \\
\hline $\mathrm{Pt}$ & 50 & $<10$ & 3.5 & 3.8 & 3.1 \\
\hline $\mathrm{Tl}$ & 50 & $<5$ & $<0.5$ & 0.11 & 0.13 \\
\hline $\mathrm{Pb}$ & 50 & $<10$ & $<0.5$ & $<0.01$ & 0.04 \\
\hline Th & $30-90$ & 59 & 66 & 62 & 62 \\
\hline
\end{tabular}

${ }^{\text {a }}$ Specification range for alloying elements and maximum value for impurity elements

${ }^{\mathrm{b}}$ May 2001

${ }^{\mathrm{c}}$ November 2001

${ }^{\mathrm{d}}$ March 2002 
Table 10. Comparison of GDMS Bulk Analyses of G2 Sheet Materials at ORNL, Y-12, and Shiva

\begin{tabular}{|c|c|c|c|c|c|c|}
\hline & & & Chen & 1 compositio & by wt & \\
\hline & Specification $^{\mathrm{a}}$ & & & $\underline{\text { Shiva }}^{\mathrm{b}}$ & $\underline{\text { Shiva }}^{c}$ & $\underline{\text { Shiva }}^{\mathrm{d}}$ \\
\hline Element & & $\underline{Y-12}$ & ORNL & & & \\
\hline B & 50 & $<5$ & $<2$ & 0.13 & 0.09 & 0.08 \\
\hline $\mathrm{Na}$ & 50 & $<5$ & $<2$ & 0.08 & 0.09 & 0.12 \\
\hline $\mathrm{Mg}$ & 50 & $<5$ & $<2$ & 0.07 & 0.02 & $<0.01$ \\
\hline $\mathrm{Al}$ & $20-80$ & 38 & 67 & 49 & 49 & 48 \\
\hline $\mathrm{Si}$ & 50 & $<5$ & 2.8 & 6.2 & 3.3 & 4.6 \\
\hline $\mathrm{S}$ & 50 & $<5$ & $<2$ & 0.02 & $<0.01$ & 0.04 \\
\hline $\mathrm{Ti}$ & 50 & $<5$ & $<2$ & 1.8 & 2.4 & 2.5 \\
\hline $\mathrm{V}$ & 50 & $<5$ & $<2$ & 0.09 & 0.13 & 0.12 \\
\hline $\mathrm{Cr}$ & 25 & $<5$ & $<2$ & 0.41 & 0.2 & 0.29 \\
\hline $\mathrm{Mn}$ & 50 & $<5$ & $<2$ & 0.05 & 0.04 & 0.04 \\
\hline $\mathrm{Fe}$ & 150 & $<5$ & 1.3 & 1.1 & 0.92 & 0.88 \\
\hline Co & 50 & $<5$ & $<2$ & 0.04 & 0.008 & 0.02 \\
\hline $\mathrm{Ni}$ & 50 & $<5$ & 0.8 & 0.7 & 0.38 & 0.4 \\
\hline $\mathrm{Cu}$ & 50 & $<5$ & $<2$ & 0.16 & 0.19 & 0.17 \\
\hline $\mathrm{Zn}$ & 50 & $<5$ & $<2$ & 0.08 & 0.05 & $<0.01$ \\
\hline $\mathrm{Y}$ & 50 & $<5$ & $<2$ & $<0.01$ & 0.01 & 0.01 \\
\hline $\mathrm{Zr}$ & 50 & $<5$ & $<2$ & 0.36 & 0.54 & 0.46 \\
\hline $\mathrm{Nb}$ & 50 & $<5$ & 0.8 & 0.57 & 0.34 & 0.39 \\
\hline Mo & 50 & $<5$ & 0.9 & 0.98 & 1 & 1 \\
\hline $\mathrm{Ru}$ & 50 & 10 & 15.2 & 15 & 14 & 15 \\
\hline $\mathrm{Rh}$ & 150 & $<5$ & 2.8 & 2.4 & 2.2 & 2.4 \\
\hline $\mathrm{Pd}$ & 50 & $<5$ & $<2$ & $<0.01$ & $<0.01$ & $<0.01$ \\
\hline In & 50 & $<5$ & $<2$ & 0.2 & 0.03 & $<0.01$ \\
\hline $\mathrm{Hf}$ & 50 & $<5$ & $<2$ & 0.096 & 0.064 & 0.084 \\
\hline $\mathrm{Ta}$ & 50 & 6 & 4.4 & $25^{\mathrm{e}}$ & 3.5 & 4.1 \\
\hline $\mathrm{W}$ & $2000-4000$ & 2910 & 2970 & 2630 & 2580 & 2650 \\
\hline $\mathrm{Re}$ & 50 & $<5$ & $<2$ & 0.17 & 0.22 & 0.21 \\
\hline Os & 50 & $<5$ & $<2$ & 0.24 & $<0.2$ & $<0.2$ \\
\hline $\mathrm{Pt}$ & 50 & 14 & 4.8 & 3.3 & 2.6 & 3.1 \\
\hline $\mathrm{Tl}$ & 50 & $<5$ & $<2$ & 0.29 & 5.8 & 0.11 \\
\hline $\mathrm{Pb}$ & 50 & $<5$ & $<2$ & 0.19 & 0.06 & 0.03 \\
\hline Th & $30-90$ & 56 & 65.4 & 50 & 59 & 59 \\
\hline
\end{tabular}

${ }^{\text {a }}$ Specification range for alloying elements and maximum value for impurity elements

${ }^{\mathrm{b}}$ May 2001

${ }^{c}$ November 2001

${ }^{\mathrm{d}}$ March 2002

${ }^{\mathrm{e}}$ The high Ta level is attributed to use of a tantalum holder which was replaced with an iridium alloy holder in subsequent analyses 
Table 11. Comparison of GDMS Bulk Analyses of MS1-1 Sheet Materials at ORNL, Y-12, and Shiva

\begin{tabular}{|c|c|c|c|c|c|}
\hline \multirow[b]{3}{*}{ Element } & & \multicolumn{3}{|c|}{ Chemical composition, ppm by wt } & \multirow{3}{*}{$\underline{\text { Shiva }}^{\circ}$} \\
\hline & Specification $^{\mathrm{a}}$ & & & $\underline{\text { Shiva }}{ }^{b}$ & \\
\hline & & $\underline{Y-12}$ & $\underline{\text { ORNL }}$ & & \\
\hline $\mathrm{B}$ & 50 & $\overline{<2}$ & $<0.5$ & 0.07 & 0.06 \\
\hline $\mathrm{Na}$ & 50 & $<2$ & $<0.5$ & 0.06 & 0.14 \\
\hline $\mathrm{Mg}$ & 50 & $<2$ & $<0.5$ & 0.03 & $<0.01$ \\
\hline $\mathrm{Al}$ & $20-80$ & 52 & 57 & 41 & 43 \\
\hline $\mathrm{Si}$ & 50 & 3 & 3.4 & 5.5 & 3.6 \\
\hline $\mathrm{S}$ & 50 & $<2$ & 0.9 & $<0.01$ & $<0.01$ \\
\hline $\mathrm{Ti}$ & 50 & $<2$ & 1.7 & 1.4 & 1.5 \\
\hline $\mathrm{V}$ & 50 & $<2$ & 0.5 & 0.81 & 1.2 \\
\hline $\mathrm{Cr}$ & 25 & 2 & 4.9 & 4.6 & 3.6 \\
\hline $\mathrm{Mn}$ & 50 & $<2$ & 0.7 & 1.3 & 2 \\
\hline $\mathrm{Fe}$ & 150 & 6 & 10.5 & 9.2 & 7.1 \\
\hline Co & 50 & $<2$ & $<0.5$ & 0.3 & 0.34 \\
\hline $\mathrm{Ni}$ & 50 & $<5$ & 1.7 & 1.2 & 1.3 \\
\hline $\mathrm{Cu}$ & 50 & $<5$ & 0.7 & 0.65 & 0.42 \\
\hline $\mathrm{Zn}$ & 50 & $<5$ & $<0.5$ & 0.14 & $<0.01$ \\
\hline Y & 50 & $<2$ & $<0.5$ & 0.02 & 0.02 \\
\hline $\mathrm{Zr}$ & 50 & 2 & 4.4 & 6.1 & 7.5 \\
\hline $\mathrm{Nb}$ & 50 & 28 & 34 & 30 & 17 \\
\hline Mo & 50 & 6 & 20 & 18 & 14 \\
\hline $\mathrm{Ru}$ & 50 & 5 & 13 & 14 & 13 \\
\hline $\mathrm{Rh}$ & 150 & $<2$ & 4.5 & 5 & 5 \\
\hline $\mathrm{Pd}$ & 50 & $<5$ & $<0.5$ & 0.03 & 0.06 \\
\hline In & 50 & $<2$ & $<0.5$ & 0.08 & 0.09 \\
\hline $\mathrm{Hf}$ & 50 & $<2$ & 0.8 & 0.78 & 0.67 \\
\hline $\mathrm{Ta}$ & 50 & 6 & 12 & 15 & 13 \\
\hline W & $2000-4000$ & 3460 & 3240 & 3050 & 3260 \\
\hline $\operatorname{Re}$ & 50 & $<2$ & 0.8 & 0.48 & 0.7 \\
\hline Os & 50 & $<2$ & 0.8 & 0.65 & 0.55 \\
\hline $\mathrm{Pt}$ & 50 & $<10$ & 8 & 8.7 & 8.2 \\
\hline $\mathrm{Tl}$ & 50 & $<5$ & $<0.5$ & 0.18 & 0.12 \\
\hline $\mathrm{Pb}$ & 50 & $<10$ & $<0.5$ & 0.01 & 0.05 \\
\hline Th & $30-90$ & 56 & 60 & 66 & 49 \\
\hline
\end{tabular}

${ }^{a}$ Specification range for alloying elements and maximum value for impurity elements ${ }^{\mathrm{b}}$ May 2001

${ }^{\mathrm{c}}$ November 2001 
Table 12. Comparison of GDMS Bulk Analyses of AR2-5

Sheet Materials at ORNL, Y-12, and Shiva

\begin{tabular}{|c|c|c|c|c|}
\hline \multirow[b]{2}{*}{ Element } & \multirow[b]{2}{*}{$\underline{\text { Specification }}^{\mathrm{a}}$} & \multicolumn{3}{|c|}{ Chemical composition, ppm by wt } \\
\hline & & $\underline{\mathrm{Y}-12}$ & ORNL & Shiva $^{\mathrm{b}}$ \\
\hline $\mathrm{B}$ & 50 & $<2$ & $<0.5$ & 0.05 \\
\hline $\mathrm{Na}$ & 50 & $<2$ & $<0.5$ & 0.48 \\
\hline $\mathrm{Mg}$ & 50 & $<2$ & $<0.5$ & 0.1 \\
\hline $\mathrm{Al}$ & $20-80$ & 53 & 63 & 66 \\
\hline $\mathrm{Si}$ & 50 & $<2$ & 3 & 2.8 \\
\hline $\mathrm{S}$ & 50 & $<2$ & $<0.5$ & 0.3 \\
\hline $\mathrm{Ti}$ & 50 & $<2$ & 1.6 & 1.7 \\
\hline $\mathrm{V}$ & 50 & $<2$ & $<0.5$ & 0.2 \\
\hline $\mathrm{Cr}$ & 25 & $<2$ & 2.1 & 2.3 \\
\hline $\mathrm{Mn}$ & 50 & $<2$ & $<0.5$ & 0.23 \\
\hline $\mathrm{Fe}$ & 150 & 5 & 9.5 & 11 \\
\hline Co & 50 & $<2$ & $<0.5$ & 0.06 \\
\hline $\mathrm{Ni}$ & 50 & $<5$ & 1.7 & 1.5 \\
\hline $\mathrm{Cu}$ & 50 & $<5$ & 0.6 & 0.49 \\
\hline $\mathrm{Zn}$ & 50 & $<5$ & $<0.5$ & 0.16 \\
\hline $\mathrm{Y}$ & 50 & $<2$ & $<0.5$ & $<0.01$ \\
\hline $\mathrm{Zr}$ & 50 & $<2$ & $<0.5$ & 0.15 \\
\hline $\mathrm{Nb}$ & 50 & $<2$ & 0.8 & 0.67 \\
\hline Mo & 50 & $<5$ & 3.7 & 4 \\
\hline $\mathrm{Ru}$ & 50 & 4 & 12 & 12 \\
\hline $\mathrm{Rh}$ & 150 & $<2$ & 0.4 & 0.46 \\
\hline $\mathrm{Pd}$ & 50 & $<5$ & $<0.5$ & $<0.01$ \\
\hline In & 50 & $<2$ & $<0.5$ & $<0.01$ \\
\hline $\mathrm{Hf}$ & 50 & $<2$ & 0.4 & 0.35 \\
\hline $\mathrm{Ta}$ & 50 & $<2$ & 4 & 3.1 \\
\hline $\operatorname{Re}$ & 50 & $<2$ & 0.4 & 0.34 \\
\hline Os & 50 & $<5$ & $<0.5$ & $<0.2$ \\
\hline $\mathrm{Pt}$ & 50 & $<10$ & 0.3 & $<0.05$ \\
\hline $\mathrm{Tl}$ & 50 & 8 & $<0.5$ & 0.16 \\
\hline $\mathrm{Pb}$ & 50 & $<10$ & $<0.5$ & 0.02 \\
\hline Th & $30-90$ & 60 & 65 & 57 \\
\hline
\end{tabular}

${ }^{a}$ Specification range for alloying elements and maximum value for impurity elements

${ }^{\mathrm{b}}$ May 2001The results for analysis of the alloying elements Al, W, and Th are summarized in Table 13 together with, where available, results of isotope dilution analysis for $\mathrm{Th}$.

A simple comparison of the results for the three alloying elements summarized in Table 13 shows that Shiva analyses are not statistically different than the ORNL and Y-12 values. This can be done by comparing each Shiva analysis for each element with both the ORNL and Y-12 values for the same material and then selecting the two values which are closest to each other. The remaining value is determined to have thegreatest variation. There are a total of 24 possible comparisons for the total of 8 Shiva analyses of the three alloying elements. In 11 of the comparisons the Y-12 value shows the greatest variation; in 10 of the comparisons the Shiva value shows the greatest variation; and in 3 of the comparisons the ORNL value shows the greatest variation. A comparison of the individual elements indicates that Y-12 shows the greatest variation for $\mathrm{Al}$, Shiva shows the greatest variation for $\mathrm{W}$, and ORNL shows the greatest variation for Th. As a whole, the Shiva results for the alloying elements, Al, Th, and W, are statistically indistinguishable from the ORNL and Y-12 results. 
An analysis of differences between the impurity contents reported in Tables 9 through 12 above is summarized in Table 14. For each analysis the percent difference between the value measured at ORNL and the value measured at Shiva was calculated. The geometric average of the differences is shown in the second column of Table 14 for each impurity element above the detectable limit. The mean impurity content measured at Shiva for all samples analyzed is listed in the third column. The number of samples analyzed for each impurity is typically eight. The results for tantalum include only the four samples analyzed with the iridium alloy sample holder. The average differences are all $50 \%$ or less. The last column of Table 14 shows a similar analysis of differences in measured values between Y-12 and ORNL. The number of elements for which comparisons are possible and the number of measurements in each average are less because in most instances the measurements from Y-12 are upper limits only. In those cases where comparisons are possible the differences between the Y-12 measurements and the ORNL measurements are generally considerably larger than the differences between the Shiva measurements and the ORNL measurements. The conclusion of these analyses is that accuracy of measurement of impurity elements by Shiva is acceptable.

Additional analyses were performed by Shiva in May 2001 on a number of samples used previously for research with intentional additions of specific elements. The results are summarized in Table 15. The E805 material had an intentional addition of $90 \mathrm{ppm}$ Th and was analyzed previously at $94 \mathrm{ppm}$ by the isotope dilution method as compared to $95 \mathrm{ppm}$ by Shiva. The sheet materials Si-15 and Si-30 were prepared with intentional additions of 15 and $30 \mathrm{ppm}$ silicon, respectively, as compared to analyzed values of 7 and $24 \mathrm{ppm}$. No analysis of the latter samples was made at ORNL or Y-12. These additional analyses do provide further confidence in the analyses performed by Shiva.

Table 13. Comparison of GDMS Bulk Analyses For Alloying Elements in Sheet Materials at ORNL, Y-12, and Shiva

\begin{tabular}{|c|c|c|c|c|}
\hline \multirow[b]{2}{*}{ Sample } & \multirow[b]{2}{*}{$\underline{\text { Site }}$} & \multicolumn{3}{|c|}{ Chemical composition, ppm by wt } \\
\hline & & $\underline{\mathrm{Al}}$ & $\underline{\mathrm{W}}$ & $\underline{T h}$ \\
\hline$\overline{\mathrm{AR} 2-5 \mathrm{~A}}$ & $\bar{Y}-12$ & 53 & 3230 & 60 \\
\hline AR2-5A & ORNL & 63 & 2980 & 65 \\
\hline AR2-5A & $\mathrm{ID}^{\mathrm{a}}$ & & & 68 \\
\hline AR2-5A & Shiva $^{b}$ & 66 & 3080 & 57 \\
\hline ER10-6 & Y-12 & 62 & 3190 & 59 \\
\hline ER10-6 & ORNL & 54 & 3120 & 66 \\
\hline ER10-6 & $\mathrm{ID}^{\mathrm{a}}$ & & & 64 \\
\hline ER10-6 & Shiva $^{b}$ & 54 & 3230 & 62 \\
\hline ER10-6 & Shiva $^{c}$ & 48 & 3260 & 62 \\
\hline G2-5-A & $\mathrm{Y}-12$ & 38 & 2910 & 56 \\
\hline $\mathrm{G} 2-5-3$ & ORNL & 67 & 2970 & 65 \\
\hline G2-5-3 & Shiva $^{\mathrm{b}}$ & 49 & 2630 & 50 \\
\hline G2-1 & Shiva $^{\mathrm{c}}$ & 49 & 2580 & 59 \\
\hline G2-1 & Shiva $^{\mathrm{d}}$ & 48 & 2650 & 59 \\
\hline MS1-1C & $\mathrm{Y}-12$ & 52 & 3460 & 56 \\
\hline MS1-1C & ORNL & 57 & 3240 & 60 \\
\hline MS1-1-3 & Shiva $^{\mathrm{b}}$ & 41 & 3050 & 66 \\
\hline MS1-1-3 & Shiva $^{c}$ & 43 & 3260 & 49 \\
\hline
\end{tabular}

${ }^{\text {a }}$ Isotope dilution method at ORNL

${ }^{\mathrm{b}}$ May 2001

${ }^{\mathrm{c}}$ November 2001

${ }^{\mathrm{d}}$ March 2002 
Table 14. Analysis of Differences in Measured Impurity Contents Between ORNL and Shiva and Between ORNL and Y-12

\begin{tabular}{|c|c|c|c|}
\hline$\underline{\text { Element }}$ & $\frac{\text { Shiva vs ORNL }}{\text { Average } \% \text { difference }}$ & $\underline{\text { Shiva Mean Content, ppm }}$ & $\frac{\mathrm{Y}-12 \text { vs ORNL }}{\text { Average } \% \text { difference }}$ \\
\hline $\mathrm{Si}$ & 33 & 4.2 & 14 \\
\hline $\mathrm{Ti}$ & 15 & 2.3 & \\
\hline $\mathrm{Cr}$ & 20 & 2.1 & \\
\hline $\mathrm{Fe}$ & 27 & 6.3 & 95 \\
\hline $\mathrm{Ni}$ & 38 & 1.3 & \\
\hline $\mathrm{Cu}$ & 37 & 0.4 & \\
\hline $\mathrm{Zr}$ & 48 & 2.0 & 120 \\
\hline $\mathrm{Nb}$ & 50 & 6.7 & 21 \\
\hline Mo & 13 & 9.0 & 233 \\
\hline $\mathrm{Ru}$ & 2 & 17.5 & 153 \\
\hline $\mathrm{Rh}$ & 16 & 4.2 & \\
\hline $\mathrm{Hf}$ & 8 & 0.7 & \\
\hline $\mathrm{Ta}^{*}$ & 7 & 5.5 & 36 \\
\hline $\operatorname{Re}$ & 23 & 0.6 & \\
\hline $\mathrm{Pt}$ & 28 & 4.7 & 190 \\
\hline
\end{tabular}

Table 15. Analysis by Shiva of Additional Samples Used in Research

\begin{tabular}{|c|c|c|c|}
\hline \multirow[b]{2}{*}{ Element } & \multicolumn{3}{|c|}{ Chemical composition, ppm by wt. } \\
\hline & $\underline{\mathrm{E} 805}$ & $\underline{\mathrm{Si}-15}$ & $\underline{\mathrm{Si}-30}$ \\
\hline $\mathrm{Al}$ & 61 & 49 & 45 \\
\hline $\mathrm{Si}$ & 6 & 7 & 24 \\
\hline $\mathrm{Fe}$ & 10 & 5 & 11 \\
\hline $\mathrm{Zr}$ & 0.1 & 4 & 9 \\
\hline $\mathrm{Nb}$ & 0.1 & 2 & 3 \\
\hline Mo & 3 & 9 & 20 \\
\hline $\mathrm{Ru}$ & 35 & 15 & 15 \\
\hline W & 2630 & 3680 & 3230 \\
\hline Th & 95 & 80 & 85 \\
\hline
\end{tabular}

\subsubsection{2"Surface" Analyses of Samples}

The "surface" analysis for sheet sample analysis is in actuality a near surface analysis of the region from 2 to $5 \mu \mathrm{m}$ from the surface. Samples were weighed at ORNL both before and after testing to determine material removal rates during the glow discharge analysis. On the basis of total glow times of 56 to 100 minutes, mass loss rates for the pins are 0.31 $\mathrm{mg} / \mathrm{min}$ with a standard deviation for 12 measurements of $0.027 \mathrm{mg} / \mathrm{min}$. Using the nominal pin geometry of $2 \mathrm{~mm}$ by $0.63 \mathrm{~mm}$ with a visible sputtered length of $6.9 \mathrm{~mm}$ results in an average calculated sputter rate of nominally 0.35 $\mu \mathrm{m} / \mathrm{min}$ at conditions $1 \mathrm{kV}$ and $3.5 \mathrm{~mA}$. The "surface" analysis is performed after the removal of about $3 \mu \mathrm{m}$ from the surface and samples material to a depth of about $5 \mu \mathrm{m}$. The sampling time for the collection of data for surface analysis therefor begins at about 10 minutes after the initiation of the glow discharge and should be completed within about 9 minutes.

The results of "surface" analyses performed at Shiva in March 2002 in accordance with the procedure MET-MatP-SOP79 draft 2/25/02 are compared with those obtained at ORNL for samples of ER10-6 and G2-1 sheet materials in Table 16. The results are in good agreement considering the variation normally seen in this analysis and the relatively high specification limits as compared to the bulk analyses. 
Table 16. Comparison of GDMS "Surface" Analyses at ORNL, Y-12, and Shiva

\begin{tabular}{|c|c|c|c|c|c|}
\hline \multirow[b]{2}{*}{ Element } & \multicolumn{5}{|c|}{ Chemical composition, ppm by wt } \\
\hline & $\underline{\text { Spec. limit }}$ & ER 10-6 ORNL & ER10-6 Shiva & G2-1 ORNL & G2-1 Shiva \\
\hline $\mathrm{Na}$ & 100 & $<5$ & 0.28 & $<5$ & 0.22 \\
\hline $\mathrm{Al}$ & 200 & 73 & 51 & 62 & 47 \\
\hline $\mathrm{Si}$ & 100 & 20 & 4.2 & $<5$ & 6.7 \\
\hline $\mathrm{Ti}$ & 100 & $<5$ & 2.3 & $<5$ & 2.5 \\
\hline $\mathrm{Cr}$ & 50 & $<5$ & 0.23 & $<5$ & 0.54 \\
\hline $\mathrm{Fe}$ & 300 & 5 & 0.93 & $<5$ & 0.88 \\
\hline Mo & 300 & $<10$ & 1.1 & $<5$ & 1 \\
\hline $\mathrm{Rh}$ & 300 & $<5$ & 2.6 & $<5$ & 2.4 \\
\hline Тa & 100 & $<5$ & 4.2 & $<5$ & 4.1 \\
\hline Th & 300 & 38 & 50 & 65 & 57 \\
\hline
\end{tabular}

\subsection{Analysis of Foil Materials}

A comparison of the analysis of foil material is shown in Table 17 for sample GFR 221 and in Table 18 for sample GFR220. An analysis of measurements of both alloying elements and impurity elements in GFR221 is summarized in Table 19. As in the case of the sheet materials, the number of elements for which comparisons between Y-12 and ORNL are possible is limited because in most instances the values from Y-12 measurements are upper limits only. The differences between the Shiva values and the ORNL values are less than the differences between the Y-12 and ORNL values for all impurity elements for which comparisons can be made and for Al. The difference between the Shiva values and the ORNL values are slightly larger than the difference between the Y-12 and ORNL values for W and for Th. These results demonstrate that accuracy of the foil analyses by Shiva is acceptable.

\subsection{Analysis of Powder Materials}

Chemical analysis is required on two types of iridium powder. Analysis is performed as part of the receiving inspection of purchased iridium powder used for production of iridium alloy blanks and foil. Analysis is also required to certify screened iridium powder for frit vent production. The level of some chemical impurities permitted in frit vent powder is lower than that permitted for purchased powder. Therefore, only the highest purity powder is selected for use in frit vents.

A comparison of GDMS analyses performed at Y-12 and at Shiva for two powder samples of unscreened purchased iridium powder is shown in Table 20. Comparisons of spark source mass spectrographic (SSMS) analyses performed by ORNL and GDMS analyses performed by Shiva on two powder samples of screened iridium powder are shown in Table 21. The elements typically detected at levels above $5 \mathrm{ppm}$ are $\mathrm{Na}, \mathrm{Si}, \mathrm{S}, \mathrm{Cl}, \mathrm{K}, \mathrm{Ca}, \mathrm{Fe}, \mathrm{Rh}$, and Pt. The analyses for $\mathrm{S}$ are in excellent agreement. The elements $\mathrm{Na}, \mathrm{Si}, \mathrm{Fe}, \mathrm{Rh}$ and $\mathrm{Pt}$ show greater variation between the two methods but without any consistent differences. The results are generally within a factor of two and in no case do the results approach the specification limits. The chlorine content of the powders is consistently analyzed at a higher level in the Shiva analysis than by the Y-12 or ORNL analyses, typically by about a factor of 4 . None of the analyses approached the specification limit of $600-\mathrm{ppm} \mathrm{Cl}$ for purchased powder, but one of the two frit vent powder samples would be rejected on the basis of the $98 \mathrm{ppm} \mathrm{Cl}$ reported by Shiva.

Additional studies have been performed to address the issue of GDMS analysis of $\mathrm{Cl}$ in iridium powder. No standard is available for $\mathrm{Cl}$ in iridium and no reference material has been used in the earlier qualification of instruments at either ORNL or Y-12. In addition, chlorine at less than $0.2 \mathrm{ppm}$ is essentially undetectable in all sheet and foil materials. For these reasons a reference powder was prepared containing an addition of nominally $700 \mathrm{ppm} \mathrm{Cl}$ added to the powder as a aqueous solution of a water soluble iridium chloride hydrate. The powder was dried and blended. The analyzed value of $\mathrm{Cl}$ this powder of $250 \mathrm{ppm}$ indicated that values reported by Shiva are not the result of an excessively large 
relative sensitivity factor. The analysis results for chlorine are restated in Table 22 for clarity. It was also noted that the GDMS analysis of one of the iridium powder samples (R12800 jar 5C) performed in 1994 at Y-12 Plant showed a large variability (see footnote to Table 22). At that time the variability was attributed to contamination from a Teflon die used to press the powder into a pin. A review of those analytical results indicates that this explains some but not all of the variation since the high $\mathrm{F}$ and $\mathrm{Cl}$ levels do not always occur in the same analysis. The general conclusion for the analysis of $\mathrm{Cl}$ in iridium powder is that the values reported by Shiva are significantly higher than those reported by ORNL or Y-12 although there is no evidence to indicate that the Shiva values are incorrect. Further, the data provides no justification for correcting the results to lower values closer to those reported by ORNL or Y-12.

The higher values of chlorine content reported by Shiva raises the possibility of decreased yields of iridium powder. One method used historically in the program to increase purity of iridium powder for blank and foil manufacture is water washing in deionized water. Water washing remains as an option in the processing of powder for blank and foil materials but has not been used for this purpose in about 20 years. For this type of powder the quantities involved and the costs of processing are large. In contrast, water washing is performed on the relatively small quantities of powder for frit vent production. Samples of both types of powder were washed in deionized water and dried as provided in the procedure for frit vent powder preparation. Samples of washed powder of one unscreened powder and one screened frit vent powder were heated at $200^{\circ} \mathrm{C}$ for one hour in both air and in vacuum. The effects of these processing steps on the chlorine content of the powder as analyzed by Shiva are shown in Table 23. In all cases water washing produces a moderate decrease in chlorine content. Heating in air or vacuum at $200^{\circ} \mathrm{C}$ do not show any consistent trend.

The conclusion, measured chlorine values are likely to be higher than those which would be obtained at either ORNL or Y-12. However, there does not appear to be any justification for correcting the Shiva measurements to lower values. This is unlikely to have any effect on blank and foil production activities or yields since chlorine in these melted products is extremely low. Powder used for blank and foil manufacture has a sufficiently high maximum specified chlorine content so that it is unlikely any purchased powder would be rejected for excessive chlorine impurity. There could be some impact on frit vent powder activities as a result of higher measured chlorine contents because fewer lots of purchased powder might be available for frit vent use. The impact on the program should be small since the needed quantities of frit vent powder are very small, measured in tens of grams per year, and there is opportunity to select the highest purity powder for frit vent use. 
Table 17. Comparison of GDMS Analyses of Foil GFR 221 at Y-12, ORNL, and Shiva

\begin{tabular}{|c|c|c|c|c|c|c|}
\hline \multirow[b]{2}{*}{ Element } & \multicolumn{6}{|c|}{ Chemical composition, ppm by wt. } \\
\hline & $\underline{\mathrm{Y}-12}$ & $\underline{\text { ORNL }}$ & $\underline{\text { Shiva }}^{\mathrm{b}}$ & $\underline{\text { Shiva }}^{\mathrm{b}}$ & $\underline{\text { Shiva }}^{\mathrm{b}}$ & $\underline{S h i v a}^{\mathrm{b}}$ \\
\hline$\overline{\mathrm{B}}$ & $\overline{<2}$ & $\overline{<0.5}$ & $\overline{0.03}$ & $\overline{0.03}$ & $\overline{0.03}$ & 0.02 \\
\hline $\mathrm{Na}$ & $<2$ & $<0.5$ & 0.09 & 0.06 & 0.04 & 0.03 \\
\hline $\mathrm{Mg}$ & $<2$ & $<0.5$ & $<0.01$ & $<0.01$ & $<0.01$ & $<0.01$ \\
\hline $\mathrm{Al}$ & 56 & 68 & 55 & 65 & 65 & 60 \\
\hline $\mathrm{Si}$ & 2 & 4.4 & 3.4 & 3.6 & 3.6 & 3.4 \\
\hline $\mathrm{Ti}$ & $<2$ & 2.5 & 1.9 & 2.1 & 2.2 & 2.3 \\
\hline V & $<2$ & $<0.5$ & 0.09 & 0.1 & 0.11 & 0.11 \\
\hline $\mathrm{Cr}$ & $<2$ & 1.2 & 0.63 & 0.71 & 0.69 & 0.66 \\
\hline $\mathrm{Mn}$ & $<2$ & $<0.5$ & 0.19 & 0.2 & 0.2 & 0.19 \\
\hline $\mathrm{Fe}$ & $<2$ & 4.8 & 2.9 & 3.1 & 3.2 & 3.1 \\
\hline Co & $<2$ & $<0.5$ & 0.02 & 0.02 & 0.02 & 0.01 \\
\hline $\mathrm{Ni}$ & $<5$ & 1.4 & 0.63 & 0.63 & 0.68 & 0.63 \\
\hline $\mathrm{Cu}$ & $<5$ & 1.2 & 0.71 & 0.78 & 0.75 & 0.68 \\
\hline $\mathrm{Y}$ & $<2$ & $<0.5$ & 0.02 & 0.02 & 0.02 & 0.02 \\
\hline $\mathrm{Zr}$ & $<2$ & 0.3 & 0.23 & 0.24 & 0.26 & 0.28 \\
\hline $\mathrm{Nb}$ & $<2$ & 0.3 & 0.14 & 0.14 & 0.15 & 0.16 \\
\hline Мo & $<2$ & 1.7 & 0.97 & 1.1 & 1.1 & 1 \\
\hline $\mathrm{Ru}$ & 11 & 28 & 22 & 23 & 24 & 24 \\
\hline $\mathrm{Rh}$ & 3 & 11 & 11 & 12 & 12 & 11 \\
\hline Hf & $<2$ & $<0.5$ & 0.25 & 0.25 & 0.25 & 0.25 \\
\hline $\mathrm{Ta}$ & $<2$ & 3 & 2.9 & 2.9 & 2.8 & 2.8 \\
\hline W & 3190 & 2940 & 2580 & 2580 & 2650 & 2650 \\
\hline $\operatorname{Re}$ & $<2$ & 0.3 & 0.22 & 0.24 & 0.23 & 0.25 \\
\hline Os & $<5$ & $<0.5$ & 0.2 & 0.25 & 0.19 & $<0.2$ \\
\hline $\mathrm{Pt}$ & $<10$ & 3.6 & 4.1 & 3.9 & 3.9 & 3.2 \\
\hline $\mathrm{Tl}$ & $<5$ & $<0.5$ & 0.03 & 0.02 & 0.03 & 0.04 \\
\hline $\mathrm{Pb}$ & $<5$ & $<0.5$ & 0.02 & 0.02 & 0.02 & 0.03 \\
\hline $\mathrm{Bi}$ & $<5$ & $<0.5$ & 0.19 & 0.21 & 0.19 & 0.2 \\
\hline Th & 22 & 26 & 20 & 21 & 20 & 23 \\
\hline
\end{tabular}

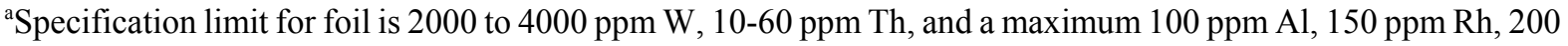
ppm $\mathrm{Fe}$, and $50 \mathrm{ppm}$ all other elements listed.

${ }^{\mathrm{b}}$ February 2002. 
Table 18. Comparison of GDMS Analyses of Foil GFR220 at Y-12 and Shiva

\begin{tabular}{|c|c|c|c|}
\hline & \multicolumn{3}{|c|}{ Chemical composition, ppm by wt. } \\
\hline Element & $\underline{\mathrm{Y}-12}$ & $\underline{\text { Shiva }}^{\mathrm{b}}$ & $\underline{\text { Shiva }}$ \\
\hline $\mathrm{Li}$ & $<2$ & $<0.01$ & $<0.01$ \\
\hline $\mathrm{Be}$ & $<2$ & $<0.01$ & $<0.01$ \\
\hline B & $<2$ & 0.16 & 0.13 \\
\hline $\mathrm{Na}$ & $<2$ & 0.26 & 0.18 \\
\hline $\mathrm{Mg}$ & $<2$ & $<0.01$ & $<0.01$ \\
\hline $\mathrm{Al}$ & 59 & 50 & 49 \\
\hline $\mathrm{Si}$ & 5 & 3.8 & 3.6 \\
\hline $\mathrm{Ti}$ & 2 & 3.2 & 3.3 \\
\hline $\mathrm{V}$ & $<2$ & 0.14 & 0.14 \\
\hline $\mathrm{Cr}$ & 2 & 11 & 11 \\
\hline $\mathrm{Mn}$ & $<2$ & 2.2 & 2.4 \\
\hline $\mathrm{Fe}$ & 56 & 39 & 39 \\
\hline Co & $<2$ & 0.14 & 0.14 \\
\hline $\mathrm{Ni}$ & $<2$ & 6.3 & 6.8 \\
\hline $\mathrm{Cu}$ & $<5$ & 0.36 & 0.36 \\
\hline $\mathrm{Y}$ & $<2$ & 0.03 & 0.03 \\
\hline $\mathrm{Zr}$ & $<2$ & 0.18 & 0.19 \\
\hline $\mathrm{Nb}$ & 3 & 3.1 & 3 \\
\hline Mo & $<2$ & 2.1 & 2.2 \\
\hline $\mathrm{Ru}$ & 7 & 13 & 13 \\
\hline $\mathrm{Rh}$ & $<2$ & 4.4 & 4.4 \\
\hline $\mathrm{Hf}$ & $<2$ & 5.4 & 5.4 \\
\hline $\mathrm{Ta}$ & $<2$ & 2.9 & 2.8 \\
\hline $\mathrm{W}$ & 3520 & 2330 & 2460 \\
\hline $\mathrm{Re}$ & $<2$ & 0.29 & 0.29 \\
\hline Os & $<5$ & 0.18 & $<0.2$ \\
\hline $\mathrm{Pt}$ & $<10$ & 6.2 & 5.2 \\
\hline $\mathrm{Tl}$ & $<5$ & 0.01 & 0.03 \\
\hline $\mathrm{Pb}$ & $<5$ & 0.06 & 0.04 \\
\hline $\mathrm{Bi}$ & $<5$ & 0.23 & 0.2 \\
\hline Th & 29 & 17 & 18 \\
\hline
\end{tabular}

${ }^{a}$ Specification limit for foil is 2000 to $4000 \mathrm{ppm} \mathrm{W,} \mathrm{10-60} \mathrm{ppm} \mathrm{Th,} \mathrm{and} \mathrm{a} \mathrm{maximum} 100 \mathrm{ppm} \mathrm{Al}, 150 \mathrm{ppm} \mathrm{Rh}, 200$ ppm Fe, and $50 \mathrm{ppm}$ all other elements listed.

${ }^{\mathrm{b}}$ February 2002. 
Table 19. Comparison of GDMS Analyses of Foil GFR221 at ORNL, Y-12 and Shiva

\begin{tabular}{|c|c|c|c|}
\hline Element & $\underline{\text { Shiva Mean ppm }}$ & $\begin{array}{c}\underline{\text { Shiva vs ORNL }} \\
\text { Average \% Difference }\end{array}$ & $\frac{\text { Y-12 vs ORNL Average \% }}{\text { Difference }}$ \\
\hline $\mathrm{Al}$ & 61 & 11 & 21 \\
\hline $\mathrm{Si}$ & 3.5 & 26 & 120 \\
\hline $\mathrm{Ti}$ & 2.1 & 18 & \\
\hline $\mathrm{Cr}$ & 0.7 & 79 & \\
\hline $\mathrm{Fe}$ & 3.1 & 56 & \\
\hline $\mathrm{Ni}$ & 0.6 & 118 & \\
\hline $\mathrm{Cu}$ & 0.7 & 65 & \\
\hline $\mathrm{Zr}$ & 0.3 & 19 & \\
\hline $\mathrm{Nb}$ & 0.1 & 104 & \\
\hline Мo & 1.0 & 63 & \\
\hline $\mathrm{Ru}$ & 23 & 21 & 155 \\
\hline $\mathrm{Rh}$ & 12 & 4 & 267 \\
\hline $\mathrm{Ta}$ & 2.9 & 5 & \\
\hline W & 2615 & 12 & 9 \\
\hline $\operatorname{Re}$ & 0.2 & 28 & \\
\hline $\mathrm{Pt}$ & 3.8 & 11 & \\
\hline Th & 21 & 24 & 18 \\
\hline
\end{tabular}


Table 20. Comparison of GDMS Analyses Of Iridium Powder As Received From Vendor For Use In Blank And Foil Manufacture

\begin{tabular}{|c|c|c|c|c|c|}
\hline \multirow{3}{*}{ Element } & \multirow{3}{*}{ Spec. ${ }^{a}$ Limit. } & \multicolumn{4}{|c|}{ Chemical Composition, ppm by wt. } \\
\hline & & & Jar 5EC & & $\underline{00 \operatorname{Jar} 21 \mathrm{~A}}$ \\
\hline & & $\underline{Y-12}$ & Shiva & $\mathrm{Y}-12$ & Shiva \\
\hline $\mathrm{Li}$ & 50 & $<2$ & 0.05 & $\overline{<2}$ & 0.07 \\
\hline $\mathrm{B}$ & 50 & $<2$ & 0.47 & $<2$ & 0.14 \\
\hline $\mathrm{F}$ & 50 & $<2$ & $<0.1$ & $<2$ & $<0.1$ \\
\hline $\mathrm{Na}$ & 100 & 43 & 52 & 49 & 22 \\
\hline $\mathrm{Mg}$ & 50 & $<2$ & 3.6 & $<2$ & 0.8 \\
\hline $\mathrm{Al}$ & 40 & 32 & 4.4 & 13 & 1.2 \\
\hline $\mathrm{Si}$ & 70 & 32 & 11 & 11 & 8.4 \\
\hline $\mathrm{P}$ & 20 & $<2$ & 0.55 & $<2$ & 0.11 \\
\hline $\mathrm{S}$ & 50 & 56 & 59 & 4 & 4.5 \\
\hline $\mathrm{Cl}$ & 600 & 19 & 66 & 20 & 43 \\
\hline $\mathrm{K}$ & 100 & 24 & 51 & $<5$ & 6.5 \\
\hline $\mathrm{Ca}$ & 70 & $<10$ & 18 & $<10$ & 1.8 \\
\hline $\mathrm{Ti}$ & 50 & $<5$ & 0.56 & $<5$ & 1 \\
\hline V & 50 & $<2$ & 0.15 & $<2$ & 0.02 \\
\hline $\mathrm{Cr}$ & 50 & $<5$ & 0.9 & $<5$ & 0.42 \\
\hline $\mathrm{Mn}$ & 20 & $<5$ & 0.38 & $<5$ & 0.28 \\
\hline $\mathrm{Fe}$ & 100 & 11 & 13 & 27 & 18 \\
\hline Co & 20 & $<2$ & 0.17 & $<2$ & 0.06 \\
\hline $\mathrm{Ni}$ & 20 & $<5$ & 1.3 & $<5$ & 0.5 \\
\hline $\mathrm{Cu}$ & 50 & $<5$ & 0.048 & $<5$ & $<0.05$ \\
\hline $\mathrm{Zn}$ & 50 & $<5$ & 0.57 & $<5$ & 0.35 \\
\hline As & 50 & $<2$ & 0.42 & $<2$ & 0.12 \\
\hline $\mathrm{Zr}$ & 50 & $<2$ & 0.07 & $<2$ & 0.21 \\
\hline Mo & 40 & $<2$ & 0.29 & $<2$ & 0.11 \\
\hline $\mathrm{Ru}$ & 50 & $<2$ & 5.6 & 6 & 24 \\
\hline $\mathrm{Rh}$ & 70 & 3 & 8.1 & 10 & 12 \\
\hline $\mathrm{Pd}$ & 50 & 5 & 3.6 & $<5$ & 0.9 \\
\hline $\mathrm{Ag}$ & 50 & $<2$ & 0.13 & $<2$ & $<0.05$ \\
\hline Sn & 50 & $<2$ & 0.68 & $<2$ & $<0.05$ \\
\hline $\mathrm{Te}$ & 50 & $<2$ & 0.46 & $<2$ & $<0.01$ \\
\hline $\mathrm{Ba}$ & 50 & $<2$ & 0.41 & $<2$ & $<0.01$ \\
\hline $\mathrm{Ce}$ & 50 & $<2$ & 0.02 & $<2$ & 0.02 \\
\hline $\mathrm{Ta}$ & 50 & 3 & $<10$ & $<2$ & $<10$ \\
\hline W & 50 & $<2$ & $<0.05$ & $<2$ & $<0.05$ \\
\hline $\mathrm{Pt}$ & 100 & $<10$ & 3.4 & $<10$ & 12 \\
\hline $\mathrm{Tl}$ & 50 & $<10$ & 0.66 & $<10$ & 0.18 \\
\hline $\mathrm{Pb}$ & 20 & $<15$ & 0.69 & $<15$ & 0.78 \\
\hline $\mathrm{Bi}$ & 50 & $<2$ & 1.4 & $<2$ & 0.42 \\
\hline
\end{tabular}

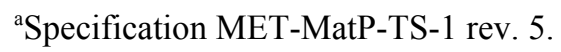


Table 21. Comparison Of Chemical Analyses Of Iridium Powder Screened To-325/+400 Mesh For Frit Vent Powder Use

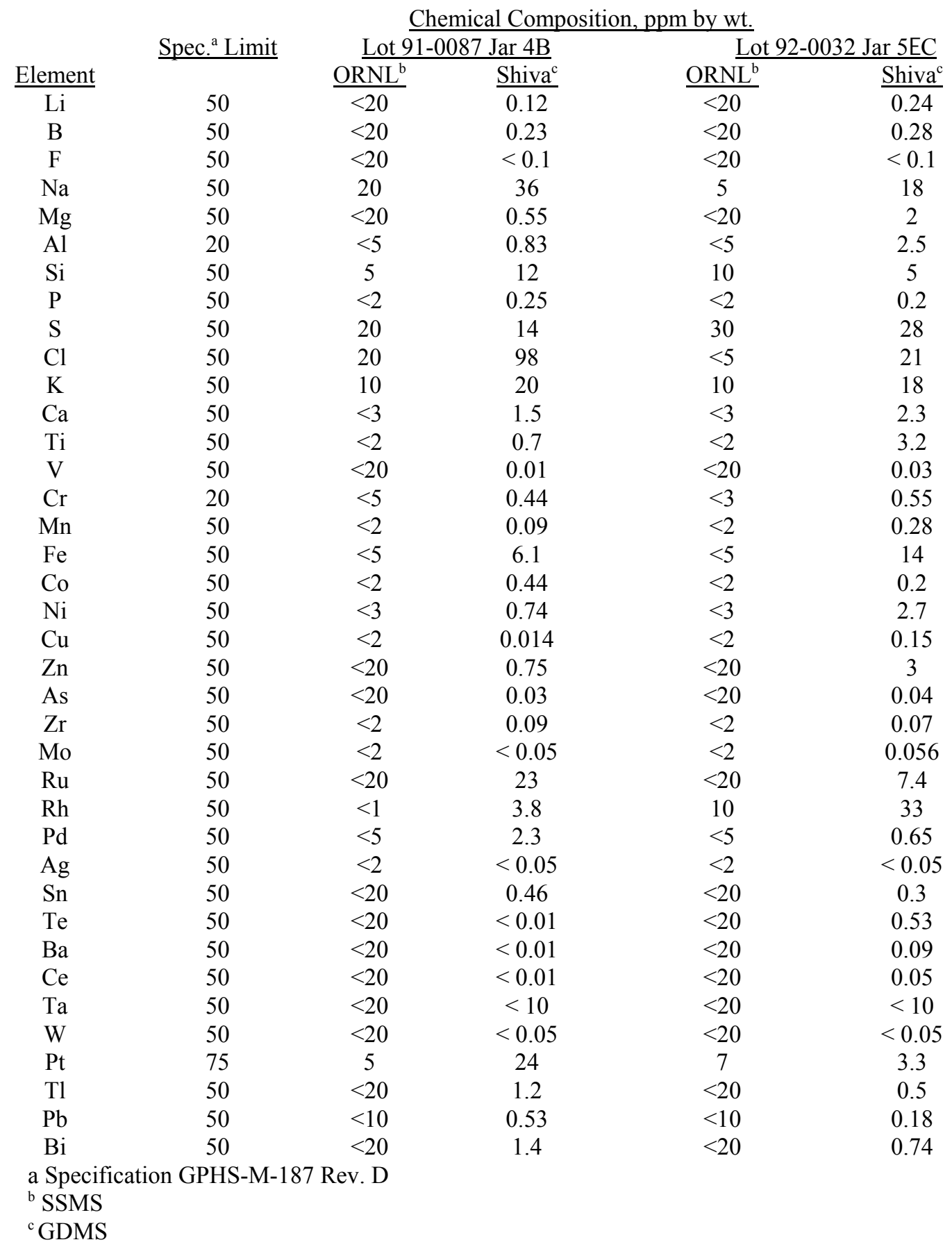


Table 22. Comparisons of Chlorine Analysis of Iridium Powder Samples

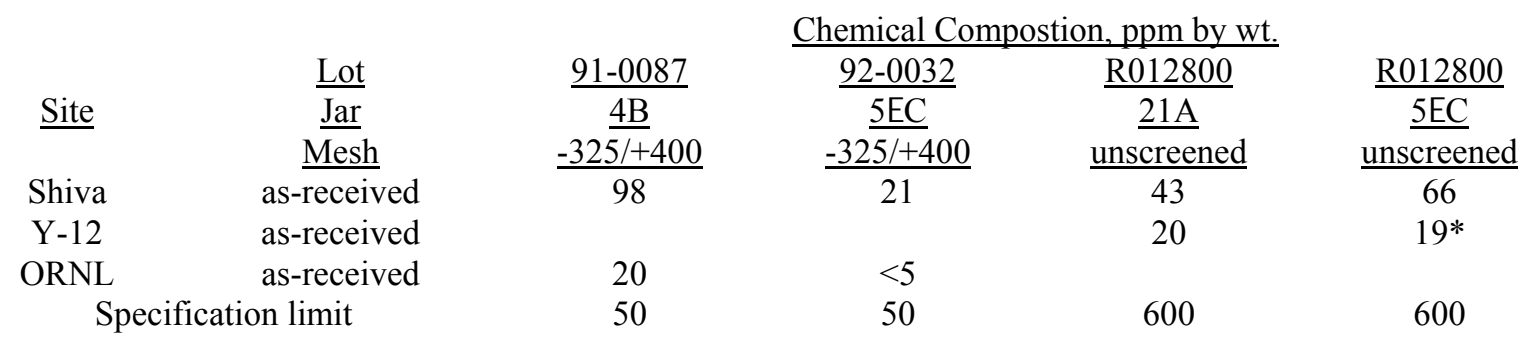

*values of $19,43,52,61,71$, obtained in repeated analyses

Table 23. Effect of Water Washing and Powder Heating on Chlorine Content of Iridium Powder Samples

\begin{tabular}{|c|c|c|c|c|c|}
\hline & & & I Compositic & y wt. & \\
\hline & Lot & 91-0087 & $\underline{92-0032}$ & $\underline{\mathrm{R} 012800}$ & $\underline{\mathrm{R} 012800}$ \\
\hline$\underline{\text { Site }}$ & $\underline{\mathrm{Jar}}$ & $\underline{4 \mathrm{~B}}$ & $\underline{5 \mathrm{EC}}$ & $\underline{21 \mathrm{~A}}$ & 5EC \\
\hline & Mesh & $-32 \overline{5 /+400}$ & $-32 \overline{5 /+400}$ & unscreened & unscreened \\
\hline Shiva & as-received & 98 & 21 & 43 & 66 \\
\hline Shiva & as-received & 98 & 21 & 43 & 66 \\
\hline Shiva & $200 \mathrm{C}$ vac & 94 & & & 26 \\
\hline Shiva & $200 \mathrm{C}$ air & 84 & & & 87 \\
\hline $\mathrm{Sp}$ & cation limit & 50 & 50 & 600 & 600 \\
\hline
\end{tabular}

\subsubsection{Quality Assurance System at Shiva Technologies}

In order to determine the adequacy of quality assurance systems in place at Shiva, a visit was made to the facility in Syracuse, NY on May 16, 2001. The visit included a tour of the laboratory and discussions with Shiva management, Richard W. Balamut, Manager Quality Assurance, Martin Kasik, Ph.D., Vice President of Operations, and Donald T. Shuman, Director Client Services. Shiva is a commercial provider of analytical chemistry services, with particular expertise in glow discharge mass spectroscopic (GDMS) analysis. They were founded about 10 years ago and moved to their current facility about 2 years ago. They have around 20 employees including two Ph.D. chemists and 4 BS chemists. They have six Fisons VG 9000 GDMS instruments at their main facility in Syracuse and additional units in France and India. The Syracuse facility includes 8000 square feet of space and includes sample preparation and cleaning facilities.

\subsection{Accreditation of Shiva by National and International Organizations}

During the visit quality documents including the results of quality audits performed by outside organizations were reviewed. Shiva is ISO 9002 accredited. Audits were performed by DLS Quality Technical Associates (Camillus, NY) in March and October 1999. Several changes and improvements were made as a results of these audits. These changes include improved documentation of operator training, operator training checklists, and written job descriptions. A follow-up audit by DLS in February 2001 showed only one minor finding which was corrected by revision to a document describing procedures for logbook issuance and archiving.

Shiva has been accredited by the National Aerospace and Defense Contractors Accreditation Program (NADCAP) since August 1999. The program for subcontractors is implemented by the Performance Review Institute, an affiliate of Society of Automotive Engineers (SAE). The audit conducted in May 1999 indicated 15 minor and one major finding. All of these were corrected or resolved to permit accreditation of the GDMS analyses performed by Shiva. As a part 
of the accreditation process an aluminum alloy reference material (Alcoa SRM \#1199) was analyzed using all six of the GDMS instruments to verify that within the uncertainty limits of the process all instruments provide equivalent results. An audit by Allied Signal (now Honeywell), Kansas City Division, Federal Manufacturing Technologies, a prime contractor to the U. S. Department of Energy, was performed on November 10, 1999. A report MA-00-0005, issued by Sharil Campbell and Kenneth Jensen, states that Shiva is an approved designated calibration source for their DOE Nuclear Weapons Standards and Calibration program.

\subsection{Detailed Description of Facilities}

Sample receiving is performed by an employee who opens the packages and accompanying documentation. The number of samples and customer sample ID's are checked against the purchase order or other documents. A job order number and Shiva sample ID number are issued and recorded. A job traveler document is issued for the job. The traveler is reviewed by a number of individuals to verify that the job can be properly performed and any special instructions are listed on the traveler. Following approval the instrument to be used is determined and the job is scheduled. A copy was provided to me of the traveler for the iridium alloy analysis performed in July 2000.

The VG9000 GDMS instruments in use at Shiva were viewed. The logbook entries for the most recent analysis of iridium alloys were reviewed. The logbook documents the instrument used and conditions of the analysis, order of sample analyses, operator, and equipment maintenance activities. Analytical results are printed from computer files and are not part of the handwritten logbook entries. Sample preparation rooms containing cutting and cleaning equipment and powder sample preparation fixtures were also visited. The rooms appeared clean and well maintained. Only iridium powder preparation will be performed at Shiva and all sheet, foil, and cup samples will be prepared and cleaned at ORNL. The powder preparation is performed inside a small plastic bag to minimize any possibility of contamination.

One room at the facility is used for storage of samples, logbooks, and records. The records are retrievable and include the peak height ratios; RSF values used, and calculated and reported analyses. I also viewed the storage area for the Shiva's standard reference materials and the documentation for those materials. The RSF values are stored in files on their internal server and can be altered only by the VP for operations. A number of files for different alloy types are stored. The iridium alloy analyses are performed using their general standard values (as opposed to those for copper alloys, for example). The general policy of Shiva is to change RSF values only on the basis of the results of at least three different standard reference materials.

\subsection{Quality Assurance Program}

The manager of Quality Assurance maintains a corrective action program. Issues relating to the quality of the analyses raised either by customers or by the analysts are documented and corrective actions are instituted and tracked. A file for each corrective action is maintained. It was explained that many of what Shiva calls corrective actions are actually non-conformances. They will be taking steps to ensure proper designation and to make certain that all nonconformances are reported to the QA manager for tracking.

Details of analyses for particular types of materials are currently controlled as ISO 9002 documents. Shiva plans to put these notes on their internal server so they will be accessible on screen for each analysis. However they will then not be ISO controlled documents. It was agreed that the procedure for analysis of iridium materials from ORNL would be a controlled document and that the cover sheet would include a sign-off by ORNL.

\subsection{Analysis Reports}

The analysis report is a two-page document. The first page will be formatted as Shiva currently formats their GDMS report. This page will also include a statement of either corrected or uncorrected data. All samples will be reported with a full analysis for uncorrected data, using the general RSF values maintained by Shiva. Samples to be certified will also be reported with corrected values using the ORNL reference materials as provided for in the procedure. These reports will include the identification of the pin samples used to perform the correction. Both bulk and surface compositions will be reported on separate sheets. The second page of all reports will include concentrations (upper limit values) for 
unstable elements Tc, Po, At, Fr, Ra, and Ac, which are not normally reported by Shiva but are required for this program. The second page of the report will also include the identification of the operator and the instrument used for the analysis, a statement of the procedure and revision number used for the analysis and the signature of the reviewer approving the report.

\subsubsection{Recommendation}

The GDMS analyses of multiple iridium alloy sheet and foil samples demonstrate that values obtained by Shiva using procedure MET-MatP-SOP-79 are equivalent to those obtained previously using approved procedures at Y-12 and ORNL. In most cases the results obtained at ORNL are closer to those obtained at Shiva than to those obtained at Y-12. In the case of iridium powder samples the results at Shiva are equivalent to those obtained at ORNL with the exception of the impurity element chlorine. The analyzed chlorine values at Shiva are higher than those at ORNL or Y-12. The use of Shiva results for chlorine would be conservative and should have no noticeable impact on product yield or production costs. An on site review of operations and quality assurance systems in place at Shiva was conducted. The conclusion of that review is that Shiva has the necessary systems to meet RPS program requirements for GDMS analysis of iridium materials.

\subsection{CLAD VENT SETS}

The goal of this activity is to produce flight quality (FQ) Clad Vent Sets (CVS) for inventory, test hardware and to maintain the production capability.

\subsubsection{Completion and Shipment of 5 FQ CVS from FY2001}

Five FQ matched CVS have been completed and readied for shipment to Los Alamos National Laboratory (LANL) to meet a milestone commitment for April. Most of this hardware was processed in FY 2001, however, vent cup assembly processing was delayed 5 months for review and subsequent approval (in February) of nonconformance report (NCR) NCR-CVS-026. This NCR addressed elevated pressures (above the 1 x $10^{-4}$ Torr procedural limit) during the frit vent assembly (FVA) vacuum sintering and diffusion bonding operations.

\subsubsection{Production and Shipment of 10 FQ CVS in FY 2002}

Twenty seven FQ cups were formed, trimmed, stripped/cleaned, heat treated for recrystallization, sized, and ground/lapped to length. Courtesy dimensional inspections for diameters, radius, wall thicknesses, height, and roundness were done after the forming, sizing, and lapping operations. Reworking for thick areas in the closure weld zones was required for all but a few of the cups. These thick areas were mostly associated with mild forming wrinkles. This reworking was done after the final courtesy inspection. The remaining fabrication operations of vent notching, dye penetrant inspection, vent hole electrical discharge machining (vent cups only), cleaning, and grit blasting, rescribing, weighing, final dimensional inspection, and final cleaning were completed.

Sixteen weld shields have been successfully butt welded and fabricated for FQ use. Three others are awaiting butt welding. Fabrication of FQ FVAs has been started after an additional two month delay for approval of deviation request DR-CVS-034 (to allow sintering and diffusion bonding vacuum pressure levels as high as $1 \mathrm{x} 10^{-3}$ Torr instead of $1 \mathrm{x}$ $10^{-4}$ Torr).

\subsubsection{Processing of Engineering Use CVS}

Four pairs of non-flight-quality or engineering use (EU) cups are being processed for eventual shipment to LANL. These cups were downgraded to EUs per SIDR-CVS-004 (dated July 10, 2001). The cups have single U-shaped impressions in their sidewalls from dried and hardened lubricant that had built up on the $2^{\text {nd }}$-form die. In retrospect it is surmised that the lubricant was being applied too early before each $2^{\text {nd }}$-form cycle. This was exacerbated when the upper stainless steel portion of the first cup formed in this campaign sheared off causing a delay, thus allowing any residual lubricant to begin to dry and harden on the heated (250EC) die. Lubricant built up more and continued to dry 
and harden on the die with each subsequent forming cycle. This was remedied for the aforementioned campaign of $27 \mathrm{FQ}$ cups by training the operator to apply lubricant to the $2^{\text {nd }}$-form die within the last 30 seconds of the preheat time and then wiping the die clean after each forming cycle.

NCR-CVS-027, was submitted and approved for shield cup 3625-31-5021 because of a thin wall condition. Four cups have already been completed as shield cup assemblies. The vent cups have been completed, however, further processing as vent cup assemblies, however, was delayed for 2 months awaiting approval of DR-CVS-034.

\subsubsection{Evaluation and Training}

Several manufacturing evaluations and training activities were conducted during the first and second quarters of FY 2002.

\subsubsection{Iridium Cup Forming Evaluation}

Twenty four non-FQ iridium cups were second-formed using various dimensions for the mild steel compensation cups to determine the effects on the final iridium alloy cup dimensions. It was hoped that this work would lead to iridium cups that would seat easier in the sizing die and that would require little or no rework for thick wall areas. During this evaluation the guide posts, bushings, and bearings were replaced in the first and second -form tooling to eliminate iridium cup dimensional variability due to worn tooling. Also, 12 sheets of $\sim 0.012$ " thick phlogopite mica were sheared, cut, drilled, and placed between each of the first- and second-form die holders and die bases. This material replaced a degraded 0.120 " thick phenolic sheet insert that apparently was used as thermal insulation between the heated die holder and the die base.

Five cups were second-formed as part of this evaluation using a new lubricant, Fiske 514A, that has replaced (on the commercial market) the currently-used Fiske 604. The new 514A lubricant has noticeably lower viscosity than the 604. This allows the new lubricant to be applied easier. Also, it may be less prone to harden and build up on the die. The dimensional results from the 5 cups formed during this evaluation with the new lubricant were similar to those with the current lubricant. The true effectiveness of this lubricant with regard to die wear is not known. Additional non-flightquality blank assemblies would have to be formed before any lubricant change could be justified. The supply of the current Fiske 604 lubricant should last approximately 10 years.

A formed mild steel cup is normally machined with an approxiamtely 0.5 Eoutside taper. This taper produces a smaller outer diameter at the open end of the mild steel cup than at the closed end. A mild steel cup is then pressed onto the straight-walled second-form punch for each iridium alloy cup that is formed. Thus, the tapered mild steel cup is used to compensate for the springback effect during warm-forming of the iridium. Mild steel cups were produced for this evaluation with tapers of 0.5 Eand $1 \mathrm{E}$ with and without removing an additional 0.005 " of material per side to achieve full clean-up, $0.5 \mathrm{E}$ with removing only an additional $0.001 "$ per side, and $1.5 \mathrm{E}$. Also, mild steel cups were used after machining to full clean-up with a straight wall as well as in the as-formed condition (tapered in the opposite direction). These tapers/conditions and the resultant outside diameters are shown in Table 1. 
Table 1. Taper/Condition and Resultant Outside Diameters (inches) of MS Cups

\begin{tabular}{|c|c|c|c|}
\hline$\underline{\text { Taper/Condition }}$ & $\frac{\text { Number }}{\text { ridimm }}$ & $\frac{\text { Open End }}{\text { Outside }}$ & $\frac{\text { Closed End }}{\text { Outside }}$ \\
\hline & $\frac{\text { of irriarum cups }}{\text { Formed }}$ & $\frac{\text { Outside }}{\text { Diameter }}$ & $\frac{\text { Outside }}{\text { Diameter }}$ \\
\hline $0.5 \mathrm{E}$ (includes 5 cups for lubricant evaluations) & 11 & 1.030 & 1.039 \\
\hline $0.5 \mathrm{E}$ in $0.001 "$ per side & 1 & 1.028 & 1.037 \\
\hline $0.5 \mathrm{E}$ in $0.005 "$ per side & 2 & 1.023 & 1.029 \\
\hline $1 \mathrm{E}$ & 2 & 1.027 & 1.042 \\
\hline $1 \mathrm{E}$ in $0.005 "$ per side & 2 & 1.020 & 1.036 \\
\hline $1.5 \mathrm{E}$ & 2 & 1.008 & 1.040 \\
\hline straight wall & 2 & 1.034 & 1.034 \\
\hline as-formed & 2 & 1.052 & 1.042 \\
\hline
\end{tabular}

The formed iridium cups were inspected for the closure weld zone diameter ( $0.4 \mathrm{~mm}$ from the open end), remainder diameter ( $6 \mathrm{~mm}$ from the open end), outside radius, outside height, minimum wall thickness, minimum and maximum wall thickness in $2.5 \mathrm{~mm}$ wide closure weld zone and roundness. These inspections were made in the as-formed condition, after sizing, and after lapping to final length.

The evaluation showed a number of notable items:

(1) As the mild steel cup open end diameter increases the as-formed iridium cup closure weld zone diameter increases (correlation coefficient $\mathrm{r} \sim 0.80$ for minimum weld zone diameter), roundness improves, i.e. decreases $(r \sim-0.68)$, and the open end wall thickness decreases $(r \sim-0.68)$;

(2) As the mild steel cup open end wall thickness increases the as-formed iridium cup closure weld zone diameter increases ( $r \sim 0.82$ for minimum weld zone diameter) [Note: this is very similar to item 1 and the reason is that the mild steel cup outer diameters and wall thicknesses are in lock-step because the mild steel cup inner diameter is held constant];

(3) As the mild steel cup taper angle decreases the as-formed iridium cup closure weld zone diameter increases $(\mathrm{r} \sim-0.79$ for minimum weld zone diameter) [Note: again this is similar to items 1 and 2 because the mild steel cup is tapered on the outside contour and, thus, the amount of taper determines the mild steel cup diameter and wall thickness at the open end], roundness improves, i.e. decreases $(\mathrm{r} \sim 0.66)$, and the wall thickness in the closure weld zone decreases $(\mathrm{r} \sim 0.70$ for maximum wall thickness in the weld zone);

(4) As the mild steel cup inside radius increases both the as-formed iridium cup outside radius $(\mathrm{r} \sim 0.71$ for the maximum outside radius) and the remainder minimum wall thickness which is located at the top of the radius increase $(\mathrm{r} \sim 0.78)$;

(5) No matter what mild steel cup dimensions are used (within the limits of the evaluation), the as-formed iridium cup dimensions (except for the closure weld zone wall thickness) are "corrected" by the sizing operation;

(6) Sizing tends to decrease the as-formed iridium cup height, improve the cup roundness, and reduce the differences between the minimums and maximums for both diameters as well as for the radius;

(7) The iridium cup wall thicknesses are established during forming and even though the grinding and lapping operations combined remove approximately $0.44 \mathrm{~mm}$ from the cup open end very little, if any, measurable wall thickness reduction occurs.

These "notable items" showed general tendencies. The correlation coefficients were not exceptionally strong because of the small number of cups evaluated with each taper/condition and fairly significant cup-to-cup variations. Nevertheless, the evaluation showed generally that mild steel cups with the $0.5 \mathrm{E}$ taper yielded as-formed iridium cups 
closer to the nominal drawing requirements than the other taper/conditions. This is good because it means less dimensional "correction" is required during sizing which means less strain and lower residual stress for the finished cups.

The mild steel cup fabrication procedure, GPHS-FABR-7735A, was modified at the end of this evaluation to revision F per DR-CVS-033 to allow the use of a hardened (57 - $62 \mathrm{HRC)}$ tool steel die (1.0498" inside diameter) instead of the worn Ampco 25 bronze die used for Cassini production in conjunction with a hardened steel punch $(0.122$ " radius and 0.9668 " diameter). Also, the mild steel cup taper ( $0.5426 \mathrm{E})$ can be machined using a computer numerical controlled machine to maintain the repeatability of the taper from campaign to campaign.

Two hundred mild steel cups were formed and fabricated. Ten percent of these were dimensionally inspected. All of these consistently met the drawing requirements. The aforementioned $27 \mathrm{FQ}$ cups for FY 2002 production were secondformed using these fabricated mild steel cups. Unfortunately, the as-formed iridium cups did not consistently seat easily in the sizing die and all but a few of the cups required some amount of rework for thick wall areas. The next forming campaign will probably be first- and second-formed with the punch temperature nominally at $260 \mathrm{EC}$ and the die nominally at $230 \mathrm{EC}$. This could produce beneficial outside diameter and wall thickness reductions of approximately $0.01 \mathrm{~mm}$.

\subsubsection{Frit Vent Backing and Cover Disc Fabrication Evaluation}

Frit vent backing discs are blanked and pierced in one operation using tooling T2E800748A048, Rev. B with a die diameter of $9.586 \mathrm{~mm}(0.3774 ")$ and punch outside diameters of $9.566 \mathrm{~mm}(0.3766 ")$ or $9.577 \mathrm{~mm}(0.3770 ")$. The production process yields parts with average maximum outside diameters of $9.598(0.3779 ")$ and average minimum outside diameters of $9.592 \mathrm{~mm}(0.3776 ")$. The part design drawing limits are 9.61/9.54 $\mathrm{mm}$. These production values are skewed to the high side of the design tolerance.

Frit vent cover discs are blanked using tooling T2E800748A018, Rev. A with die diameters of $9.538 \mathrm{~mm}\left(0.3755^{\prime \prime}\right)$ or $9.545 \mathrm{~mm}\left(0.3758^{\prime \prime}\right)$ and punch diameters of $9.520 \mathrm{~mm}(0.3748 ")$ or $9.522 \mathrm{~mm}(0.3749 ")$, respectively. Cover discs are pierced in a separate operation using tooling T2E-139756, Rev. A. The production process yields parts with average maximum outside diameters of 9.585 (0.3774") and average minimum outside diameters of $9.574 \mathrm{~mm}\left(0.3769^{\prime \prime}\right)$. The part design drawing limits are the same as for the backing discs, $9.61 / 9.54 \mathrm{~mm}$. These cover disc production values are slightly skewed to the high side of the design tolerance.

New frit vent backing and cover disc blanking dies and punches were evaluated to produce finished part outside diameters closer to the nominal $9.575 \mathrm{~mm}(0.3770 ")$ requirements. Also, it was desired to have cleanly sheared outside edges that required little or no deburring. Unfortunately, the new frit vent backing disc dies $9.558 / 9.563 \mathrm{~mm}$ $(0.3763 " / 0.3765 ")$ and punches $9.543 / 9.545 \mathrm{~mm}(0.3757 " / 0.3758 ")$ yielded poorly sheared edges. These edges required extensive deburring and/or their diameters were not uniform.

A new hold-down/stripper plate was fabricated with a central hole diameter of $9.583 \mathrm{~mm}(0.3773 ")$ instead of the original $9.700 / 9.726 \mathrm{~mm}\left(0.3819^{\prime \prime} / 0.3829 "\right)$. This was done with the idea that reducing the gap between the die and hold down/stripper plate would yield a better sheared edge. Distortion was reduced slightly in the surrounding foil stock, however, the ragged blank edges were unchanged. Because of these results additional tooling was designed and fabricated to pierce the backing disc central hole in a separate operation. Thus, both the cover disc and backing disc would be blanked from the same tooling, T2E800748A018, with excellent edges.

The new frit vent backing disc piercing tooling was received and evaluated. It was anticipated that using the same new blanking tooling for both the backing and cover discs would make the outer diameters even more similar and closer to the nominal drawing requirement without deburring. After a number of iterations a die diameter of $9.533 \mathrm{~mm}(0.3753 ")$ and a punch diameter of $9.525 \mathrm{~mm}\left(0.3750^{\prime \prime}\right)$ yielded finished (after piercing and compressing) average maximum/minimum outer diameters of $9.575 / 9.566 \mathrm{~mm}(0.3770 " / 0.3766 ")$ and $9.591 / 9.576 \mathrm{~mm}(0.3776 " / 0.3770 ")$ for the backing and cover discs, respectively. 
Interestingly, the backing disc and cover disc diameters are different after their piercing operations. The backing disc diameters were consistently smaller than the cover disc diameters for each tooling iteration evaluated. The aforementioned blanking die and punch diameters center the combined backing and cover disc processes around the nominal design drawing requirement. The backing disc process is slightly below the nominal requirement, but with no minimum value too close to the lower limit. The cover disc process is slightly above the nominal requirement, but with no maximum value too close to the upper limit. As a matter of fact the backing disc minimums are above the design minimum about as much as the cover disc maximums are below the design maximum. The backing and cover disc edges are excellent, so that no deburring is required and dimensional measurements are straightforward. Deviation requests will be written to modify both the backing and cover disc fabrication procedures.

\subsubsection{Training}

Training of back-up personnel for the cup fabrication operations of recrystallization, grinding, lapping, vent notching, electrical discharge machining of the vent hole, and the mild steel cup tapering operation was conducted. Also, back-up personnel were trained for cup dye penetrant inspection. Extensive training was performed for FVA fabrication. 


\section{BASE TECHNOLOGY PROGRAM AND TECHNICAL SUPPORT ACTIVITIES}

\subsection{TECHNICAL SUPPORT FOR ADVANCED RADIOISOTOPE POWER SYSTEM (ARPS) AMTEC CELL DEVELOPMENT}

\subsubsection{Introduction}

The ARPS Program is developing the AMTEC converter as a possible thermal-to-electric power conversion technology in generators for outer planetary space missions being considered for NASA. These converters are fabricated from refractory metal alloys and use sodium $(\mathrm{Na})$ as a working fluid with beta alumina solid electrolyte. ORNL is providing technical support to the AMTEC development program by producing Mo- $41 \%$ Re alloy ingots and processing them to various product forms, performing welding fabrication development for the converters with the electron beam (EB) welding process, and developing ceramic insulator to refractory alloy brazing alloys for the electrical feed throughs. The AMTEC Program is currently developing a "chimney design" fabricated from the Mo- $41 \% \mathrm{Re}$ alloy and demonstrating its improved conversion efficiency.

\subsubsection{Molybdenum-41\% Rhenium Alloy Production}

Tables 1 and 2 list the Mo-41\%Re shipped and the chemical composition of the material, respectively.

Table 1. Mo-41\%Re shipped to AMPS during the first half of FY 2002

\begin{tabular}{|c|c|c|c|c|}
\hline$\underline{\text { Date }}$ & Quantity & Product & Identify & $\underline{\text { Dimensions }}$ \\
\hline $10 / 24 / 01$ & 1 & rod & $\overline{M R 4-1}$ & $0.201 "$ diam x 18 " long \\
\hline $01 / 31 / 02$ & 2 & plates & MR6-6 & $2.5^{\prime \prime}$ square $\times 0.40 "$ thick \\
\hline 03/11/02 & 10 & disks & MR6-1,-2,-3 & $3.5 "$ diam $x 0.040 "$ thick \\
\hline $03 / 22 / 02$ & 9 & disks & MR6-1,-4,-5 & $5.75^{\prime \prime}$ diam $\times 0.040 "$ thick \\
\hline
\end{tabular}

The rod and plate materials were supplied in a recrystallized condition with a final recrystallization heat treatment at $1400^{\circ} \mathrm{C}$ for 1 hour. The disk materials were supplied in a stress relieved condition with a final heat treatment at $1000^{\circ}$ $\mathrm{C}$ for 1 hour. The processing of these materials and product forms was the same as described in previous reports.

Table 2. Chemical Composition by Weight of Shipped Mo-41\%Re

$\begin{array}{ccc}\text { Element } & \underline{\text { MR6 }} & \underline{\text { MR4 }} \\ \text { Rhenium } & 42.0 \% & 41.3 \% \\ \text { Carbon } & 85 \mathrm{ppm} & 104 \mathrm{ppm} \\ \text { Oxygen } & 11 \mathrm{ppm} & 7 \mathrm{ppm} \\ \text { Molybdenum } & \text { Balance } & \text { Balance }\end{array}$

Analyses were made using a glow discharge mass spectrograph except for the carbon and oxygen analyses of MR4 which were measured by combustion.

The MR7 ingot was prepared for extrusion. The ingot was machined and a molybdenum extrusion can was prepared. The extrusion is to provide additional plate material of 0.38 in. thickness.

\subsubsection{AMTEC Cell Fabrication Development}

A test was performed to determine if the EB weld penetration into the BASE support plate may have extended into the sodium duct of this component due to the preheat effect of making several welds in close succession. Six BASE tube covers were welded in a development BASE support plate using the same welding parameters and essentially the same welding sequence used on the SP-1 converter. No weld penetration into the sodium duct was found in any of the six 
welds. Based on the results of this test, it appears unlikely that the weld penetrated sufficiently to obstruct the sodium duct.

Development test specimens were welded and evaluated for the SP-2 converter. These included various welds for the cell walls and the pump out port to weld button. The pump out port welds between Mo and $\mathrm{Nb}$ had good visual appearance as shown in Figure 1, but cracking was found during metallographic examination. Previously, preliminary welding tests on sheet specimens of these two materials with an edge weld joint had not exhibited cracking. The higher restraint of these circular weldments between the pumpout port tube and the weld button probably contributed to the observed cracking. The design is being reevaluated by AMPS.

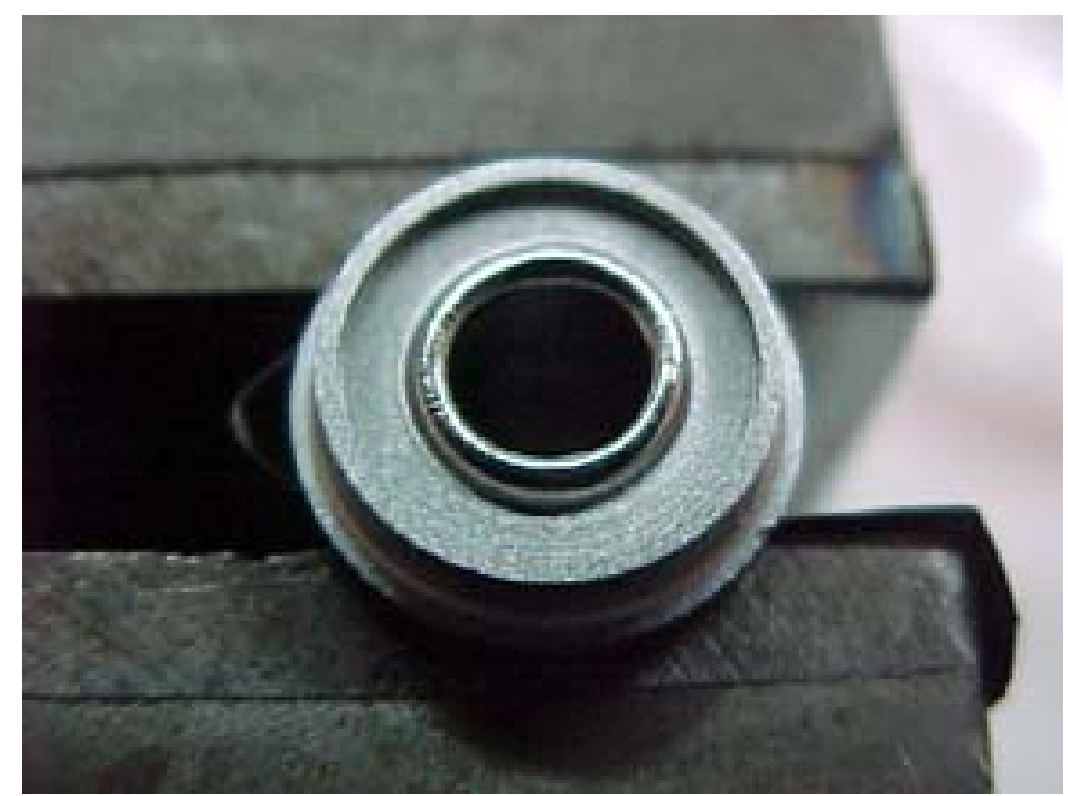

Figure 1. Electron beam welded niobium pumpout port to molybdenum weld button.

Subassemblies of the SP-2 converter were shipped to Oak Ridge for assembly and welding prior to all the converter components being completed. The mounting stud welds were welded into the condenser cap. Also, the lower cell wall, transition piece, and upper cell wall were joined to produce a subassembly for the SP-2. These subassemblies were returned to AMPS for leak testing and trial fitting with the remainder of the components. The SP-2 converter was assembled by AMPS personnel and electron beam welded at ORNL during February. Welding of the Mo- $41 \%$ Re converter components was performed using the welding parameters which had previously been developed for this material and configuration. It was noticed after welding that two BASE tube insulators were cracked. Welding of the converter was completed. The measured leak rate of the completed assembly was $6 \times 10^{-8} \mathrm{std}$.-cc/s He.

Proposed design modifications to the BASE support plate were reviewed and discussed with AMPS personnel. The modifications are intended to reduce the welding distortion which results from the extensive welding that occurs on this component. It does not appear that the modification would significantly impact the welding of the BASE tube subassemblies to the BASE support plate. It was recommended that a welding test be performed on the proposed joint geometry prior to fabricating a converter.

A cost estimate for producing nine ingots of Mo- $41 \%$ Re and processing it to various stock material forms was prepared at the request of AMPS for their total cost projections for future years of AMTEC converter development. These ingots would produce enough material for approximately twenty AMTEC converters of the SP design. 
The new mechanical vacuum pump system for the electron beam welder has been returned to ORNL and reinstalled. After the initial installation of these pumps last year, they were found to produce a very high pitched noise which was related to the gears. Contact with the factory representatives revealed this to be a new generic problem as a result of a change in gear supplier. The gears were changed, and the problem has been corrected.

\subsubsection{Brazing Development for AMTEC}

The experiments to evaluate filler metal alloys for brazing MoRe alloy sheet to $\alpha-\mathrm{Al}_{2} \mathrm{O}_{3}$ are proceeding in two areas. Initial wetting experiments indicated that a braze alloy of Ti-48Zr-4Be wt $\%$ had a contact wetting angle of $45-50^{\circ}$ on $\mathrm{Al}_{2} \mathrm{O}_{3}$. Furthermore, solidified droplets of this alloy were adherent to $\mathrm{Al}_{2} \mathrm{O}_{3}$ surfaces and free of cracks. Because the braze alloy is nominally $96 \mathrm{wt} \%$ refractory metal, it should be resistant to corrosion attack by liquid sodium. Based on these considerations, the TiZrBe alloy was selected for subsequent brazing evaluation. Many t-joints of $\mathrm{MoRe}$ to $\mathrm{Al}_{2} \mathrm{O}_{3}$ have now been brazed in the temperature range of $1170-1200^{\circ} \mathrm{C}$. Typically, the joints have good visual appearance in that the filler metal produces a uniform fillet and it flows in the joint gaps. Generally the joints have no sign of porosity. The joint strength has not been measured, but it appears to be relatively high. The joints survive routine handling and cutting for metallographic specimen preparation. A series of t-joints brazed with TiZrBe filler metal were made and are being held for Na exposure testing. Molybdenum tubing and sheet was acquired and used to machine parts for the Mo canisters required for the $\mathrm{Na}$ exposures.

In the companion experiments, a series of experimental alloys is being evaluated as possible filler metals for the MoReto- $\mathrm{Al}_{2} \mathrm{O}_{3}$ joints. A summary of results is presented in Table 3. The criteria used to selected these alloy compositions were described in previous reports. The evaluation consists of melting the alloys on $\mathrm{Al}_{2} \mathrm{O}_{3}$ while estimating their melting temperatures and measuring their wetting contact angles. Alloys with unacceptable high wetting angles, $>60^{\circ}$, or that formed solidified droplets containing extensive cracking, or droplets that did not adhere to the $\mathrm{Al}_{2} \mathrm{O}_{3}$ were rejected from further consideration. These are referred to as "no-go" conditions in Table 1. MoRe-to- $\mathrm{Al}_{2} \mathrm{O}_{3}$ joints are being made from the alloys with acceptable wetting. Joints referred to as "no-go" condition in Table 1 suffered from either poor fillet formation, poor filler metal adherence, or poor filler metal strength. All of these conditions were associated with inability to handle the joints without breaking them. 
Table 1. Experimental Braze Filler Metal Alloys and Their Measured Melting Temperatures

\begin{tabular}{|c|c|c|c|}
\hline$\frac{\text { Alloy, }}{\text { nominal wt } \%}$ & $\underline{\frac{\text { Approx. }}{\text { melting temp. }} .{ }^{\circ} \mathrm{C}}$ & $\frac{\text { Wetting, }}{\text { Go/no-go }^{\text {a }}}$ & $\underline{\text { Brazing }}$ \\
\hline $\mathrm{Ni}-14 \mathrm{Ti}$ & 1330 & & \\
\hline $\mathrm{Ni}-34 \mathrm{Ti}$ & 1150 & Go, $36^{\circ}$ & \\
\hline $\mathrm{Ni}-67 \mathrm{Ti}$ & 980 & & \\
\hline $\mathrm{Ni}-72 \mathrm{Ti}$ & 1070 & Go, $25^{\circ}$ & No-go \\
\hline $\mathrm{Ni}-13 \mathrm{Zr}$ & 1200 & $\mathrm{Go}, 53^{\circ}$ & Go \\
\hline $\mathrm{Fe}-14 \mathrm{Ti}$ & 1320 & Go, $39^{\circ}$ & No-go \\
\hline Co-20Ti & 1210 & No-go, $68^{\circ}$ & \\
\hline Co-44Ti & 1505 & Go, $29^{\circ}$ & No-go \\
\hline Co-74Ti & 1020 & Go, $30^{\circ}$ & No-go \\
\hline Co-10Zr & 1400 & No-go, $138^{\circ}$ & \\
\hline $\mathrm{Co}-14 \mathrm{Zr}$ & 1232 & No-go, $110^{\circ}$ & \\
\hline Co-20Cr-25Ti & 1325 & Go, $30^{\circ}$ & No-go \\
\hline Co-20Cr-20Ti & 1275 & Go, $49^{\circ}$ & No-go \\
\hline Co-20Cr-15Ti & NA & No-go, $63^{\circ}$ & \\
\hline Co- $15 \mathrm{Cr}-25 \mathrm{Ti}$ & 1300 & Go, $20^{\circ}$ & \\
\hline Co-15Cr-20Ti & 1255 & NA & \\
\hline Co-30Cr-10Ti & NA & No-go, $>90^{\circ}$ & \\
\hline Co-18Cr-16Ti & NA & No-go, $121^{\circ}$ & \\
\hline
\end{tabular}

${ }^{\text {a }}$ Wetting behavior was evaluated by melting on $\alpha-\mathrm{Al}_{2} \mathrm{O}_{3}$. Go condition for wetting means the alloy had a contact angle on the $\mathrm{Al}_{2} \mathrm{O}_{3}$ of less than $60^{\circ}$.

b Brazing behavior was evaluated by making a t-joint of MoRe alloy on a- $\mathrm{Al}_{2} \mathrm{O}_{3}$ by vacuum furnace brazing. Go condition means the joint appearance was good and the joint survived routine handling. 


\subsection{ALLOY DEVELOPMENT AND CHARACTERIZATION}

\subsubsection{Impact Properties of DOP-26 Iridium Doped with 15-50 wppm Si}

A recent study found that silicon can severely embrittle DOP-26 iridium if present as an impurity in concentrations of greater than approximately $500 \mathrm{wppm}[1,2]$. In addition, silicon additions of 50 to $500 \mathrm{ppm}$ were found to produce ductilities close to the lower end of the ductility range of the Si-free alloys [1]. The embrittlement was shown to be related to Si-induced grain coarsening combined with the segregation of Si to the grain boundaries [2], where it displaces beneficial Th and forms a low-melting eutectic. Silicon was found to segregate to the grain boundaries even when present at levels as low as $50 \mathrm{ppm}$ in the bulk. Since this is the upper limit of silicon in the DOP-26 specification [3], a better understanding of the effects of lower amounts of silicon on grain size, impact ductility, and weldability is needed. The purpose of this report is to summarize the results of high strain rate impact tests of DOP-26 iridium containing 15, 30, and 50 wppm Si.

Five-hundred-gram heats of DOP-26 iridium alloy (nominal composition, Ir-0.3W-0.006Th-0.005Al, wt.\%) with nominal additions of 15 (heat \#18035), 30 (heat\#18034), and 50 (heat\#17390) wppm Si were arc melted and drop cast using the old-process as described in Refs. 4 and 5. They were then rolled to 0.86-mm-thick sheet as described in Ref. 4. Specimens for high-temperature tensile impact testing were machined from the rolled sheets and annealed for $19 \mathrm{~h}$ at 1500 EC. Using the tensile impact tester at Oak Ridge National Laboratory [6,7], impact testing was carried out at a test temperature of $980 \mathrm{EC}$ (controlled to within $\pm 10 \mathrm{EC}$ ) and at a constant bullet velocity of $61 \pm 3 \mathrm{~m} / \mathrm{s}$ (which corresponds to an engineering strain rate of $\sim 10^{3} \mathrm{~s}^{-1}$ within the specimen gage sections). At least three tests were performed at each impurity level and the average impact elongations were calculated. Scanning electron microscopy (SEM) was used to examine the fracture surfaces.

In order to determine the effect of the impurity addition on grain size, samples were cut from the undeformed grip ends of impact specimens and metallographically polished and electrolytically etched in a solution of $400 \mathrm{ml} \mathrm{H}_{2} \mathrm{O}, 100 \mathrm{ml}$ $\mathrm{HCl}$, and $2.5 \mathrm{~g} \mathrm{NaCl}$, using a current of $0.9 \mathrm{~A}$ at an applied potential of approximately $10 \mathrm{~V} \mathrm{AC}$ for $4-5 \mathrm{~min}$. Grain sizes were measured by the method of linear intercepts in a plane transverse to the rolling direction, in a direction perpendicular to the plane of the sheet (short transverse direction). Grain size measurements were recorded as the average values obtained from two fields in each specimen.

The results of impact tests are pesented in Table I. The average impact ductility of the $15 \mathrm{ppm}$ Si alloy was $13.1 \%$, of the $30 \mathrm{ppm}$ Si alloy $6.0 \%$, and of the $50 \mathrm{ppm}$ Si alloy 5.7\%. A study of the fracture surfaces using SEM (see Fig. 1) showed an inverse correlation between the percentage of transgranular facets present on the fracture surface and the amount of Si doping. The alloy doped with $15 \mathrm{ppm} \mathrm{Si} \mathrm{contained} \mathrm{several} \mathrm{transgranular} \mathrm{facets} \mathrm{while} \mathrm{fracture} \mathrm{in} \mathrm{the} \mathrm{alloy}$ containing $50 \mathrm{ppm}$ Si was almost totally intergranular.

Table I. Effect of Si Addition on Grain Size and Impact Ductility of DOP-26 Iridium

\begin{tabular}{|c|c|c|c|}
\hline Heat Number & Nominal Si Content (wppm) & $\underline{\text { Average Grain Size }(\mathrm{Fm})^{\mathrm{a}}}$ & Impact Elongation $(\%)^{\mathrm{b}}$ \\
\hline \multirow[t]{3}{*}{18035} & 15 & $34 \pm 6(180)$ & 9.5 \\
\hline & & & 17.0 \\
\hline & & & 12.9 \\
\hline \multirow[t]{3}{*}{18034} & 30 & $41 \pm 4$ (148) & 5.4 \\
\hline & & & 6.5 \\
\hline & & & 6.0 \\
\hline \multirow[t]{7}{*}{17390} & 50 & $49 \pm 9(252)$ & 10.0 \\
\hline & & & 6.8 \\
\hline & & & 5.7 \\
\hline & & & 6.9 \\
\hline & & & 3.4 \\
\hline & & & 2.5 \\
\hline & & & 4.7 \\
\hline
\end{tabular}



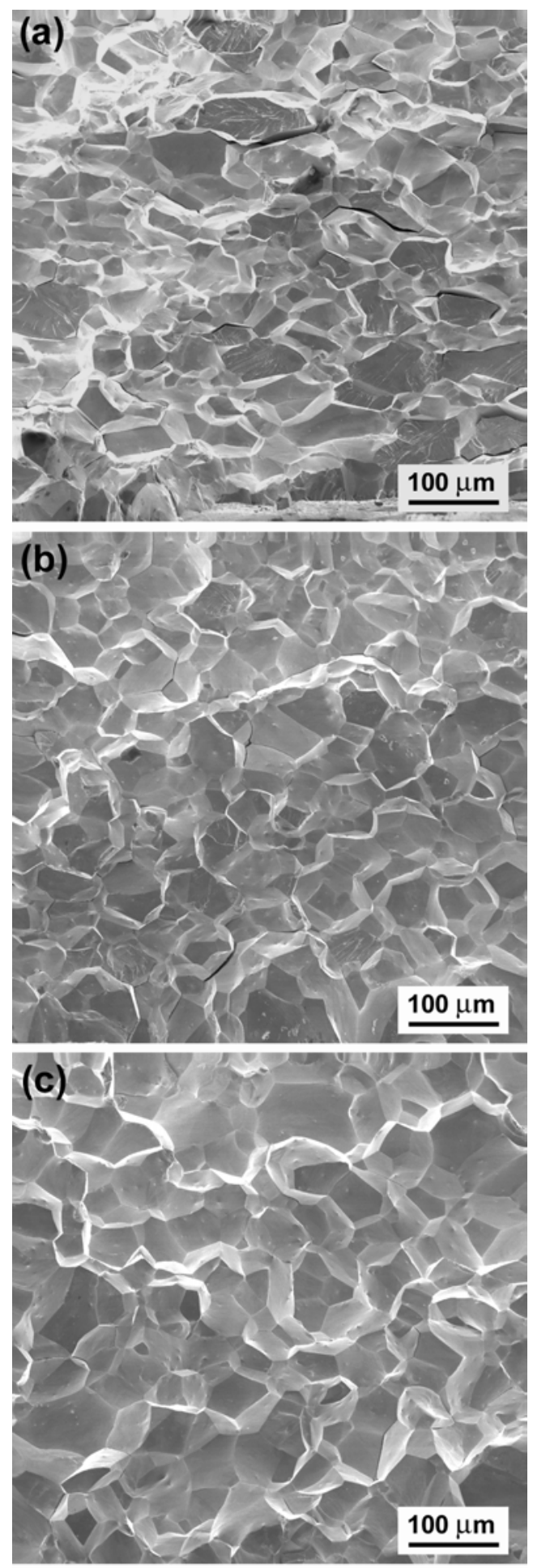

Fig. 1. Scanning electron micrographs showing the effect of Si doping on the fracture mode of DOP-26: (a) 15, (b) 30, and (c) $50 \mathrm{wppm} \mathrm{Si}$. 
The optical microstructure of each alloy is shown in Fig. 2. The average grain sizes are listed in Table I. The average grain size tended to increase with increasing Si content, starting at $34 \mathrm{Fm}$ for the $15 \mathrm{ppm} \mathrm{Si}$ alloy and increasing to 49 $\mathrm{Fm}$ for the $50 \mathrm{ppm} \mathrm{Si}$ alloy. This value for DOP-26 containing $50 \mathrm{ppm} \mathrm{Si}$ substantiates a previous measurement reported for this same heat annealed for $18 \mathrm{~h}$ at $1500 \mathrm{EC}$ [8]. The decrease in ductility and the transition to a more brittle intergranular mode as the Si concentration increases from 15 to $50 \mathrm{ppm}$ may be due partly to grain coarsening. But it may also be related to the effects of the different $\mathrm{Si}$ levels on grain-boundary cohesion. To distinguish between these two possibilities, additional impact tests will be performed in which grain size is systematically varied in each of the Si-containing alloys. Meanwhile, though, it is clear from the present results that Si concentrations in the range 30-50 ppm are deleterious to the impact ductility of DOP-26 iridium.
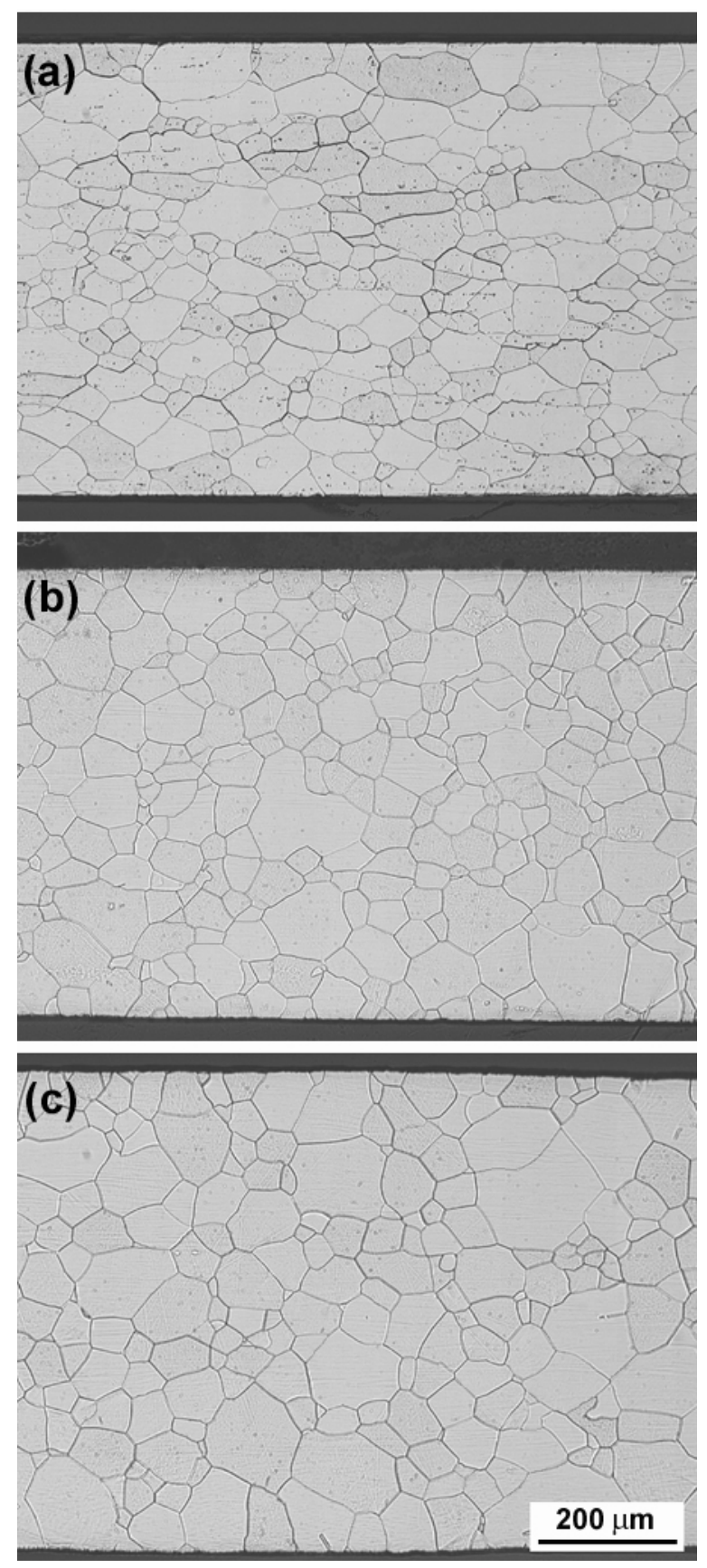

Fig. 2. Optical micrographs showing the grain sizes of DOP-26 with nominal Si additions of (a) 15, (b) 30 , and (c) $50 \mathrm{wppm}$. 
In summary, the results of this study show a trend toward larger grain size, lower ductility and a more brittle fracture as the silicon concentration is increased from 15 to $50 \mathrm{wppm}$. Silicon concentrations in the range $30-50 \mathrm{ppm}$ lowered the impact ductilities to $\sim 6 \%$, which is considerably below the $13.5 \%$ required for qualification of production heats of DOP-26 iridium and also below typical ductilities $(4,6,7)$ obtained in old-process DOP-26 containing no intentionally added silicon. These results may indicate the need to lower the level of allowable Si in DOP-26 to a level below that which is currently allowed $(<50 \mathrm{ppm})$. However, before we can specify what this new level should be, we need to perform additional tests on the 15 and $30 \mathrm{ppm}$ Si alloys to obtain better statistics. We also need to test alloys containing $<15 \mathrm{ppm}$ Si because the impact ductility of even the $15 \mathrm{ppm}$ Si alloy ( 13\%) appears to be marginal. Both sets of tests are planned for FY 2002 after which we should be able to recommend a new specification for Si in DOP-26 iridium. It should be noted that all of the production heats of DOP-26 produced during the last 10-15 years have contained much less than 15 wppm Si.

References

1. C. G. McKamey, E. P. George, E. H. Lee, E. K. Ohriner, L. Heatherly, and J. W. Cohron, "Impurity Effects on High-Temperature Tensile Ductility of Iridium Alloys at High Strain Rate," Scripta Mater. 42, 9-15 (2000).

2. L. Heatherly and E. P. George, "Grain Boundary Segregation of Impurities in Iridium and Effects on Mechanical Properties," Acta Mater. 49, 289-98 (2000).

3. Document No. GPHS-M-185 Rev. D., "General Purpose Heat Source Material Specification - Iridium Blanks," Oak Ridge National Laboratory, Oak Ridge, TN, August 1994.

4. C. G. McKamey, A. N. Gubbi, Y. Lin, J. W. Cohron, E. H. Lee, and E. P. George, Grain Growth Behavior and High-Temperature High-Strain-Rate Tensile Ductility of Iridium Alloy DOP-26, ORNL-6935 (Oak Ridge National Laboratory, Oak Ridge, TN, April 1998).

5. E. K. Ohriner and E. P. George, "Plan to Evaluate Effects of Intermetallic Particle Distribution on Properties of DOP-26 Iridium Alloy," attachment to Letter No. 0719-66-91, M. M. Martin to W. J. Barnett, July 19, 1991.

6. C. T. Liu and H. Inouye, Development and Characterization of an Improved Ir-0.3\% W Alloy for Space Radioisotopic Heat Sources, ORNL-5290 (Oak Ridge National Laboratory, Oak Ridge, TN, October 1977).

7. C. T. Liu, H. Inouye, and A. C. Schaffhauser, Metall. Trans., 12A (1981) 993.

8. C. G. McKamey, E. P. George, J. L. Wright, E. H. Lee, and E. K. Ohriner, "Grain Growth of DOP-26 Doped with 50 wppm Si," attachment to letter, J. P. Moore to W. J. Barnett, May 31, 2000. 


\subsection{PLUTONIUM PRODUCTION STUDIES}

\subsection{TARGET DEVELOPMENT}

\subsubsection{Array Target Post Irradiation Examination}

The array targets were irradiated for two cycles in a large "B" position in the Advanced Test Reactor (ATR) at INEEL. The irradiation ended in early November 2001 and the targets were discharged. The targets cooled until early March 2002 when they were transferred to a shipping cask and shipped to ORNL for examination. The cask containing the targets was transferred into hot cells at ORNL Building 3525 where they were removed from the cask. The cask was transferred out of the cell, decontaminated, and shipped back to GE. The targets were visually inspected to look for damage and verify target identification. The targets will be drilled open during the next quarter to provide information on fission gas release during irradiation.

\subsubsection{ATR Production Calculations}

Concepts for target design have been drawn and used as input to finite element mechanical engineering models. The modeling is to verify target integrity during routine handling operations. The benchmark is currently the HFIR targets. Under the assumption that if the new targets are as robust as HFIR targets, they should survive routine handling during cask loading and unloading. Once the concept for target design has been completed, the ATR staff will develop expected ${ }^{238} \mathrm{Pu}$ production rates and ${ }^{236} \mathrm{Pu}$ levels for each irradiation position.

The initial computational effort by ATR staff is focused on developing as-run calculations for the pellet and array targets. The as-run calculations will then use a variety of cross-section data sets. This will allow comparison of predicted data to actual data for a variety of data sets and will allow selection of the data set providing the best agreement between predicted and actual data.

\subsubsection{Neptunium Gas Generation During Storage Studies}

Safety issues concerning transportation and long-term storage of neptunium are of a particular concern to the program. Current safety analyses must assume all of the water absorbed on the surface of the $\mathrm{NpO}_{2}$ can be broken down by radiolysis into gaseous hydrogen and oxygen thus generating significant gas pressures within the storage containers. Also, the potential for detonation of the hydrogen has been identified as a safety issue for transportation. However, experimental work by Icenhour ${ }^{(1,2,3)}$ using uranyl salts has demonstrated that radiolysis does not go to completion and that competitive reactions cause the vessel pressure to plateau at a much smaller total pressure. In some cases, the vessel actually goes to vacuum conditions, hence, this set of experiments is designed to irradiate $\mathrm{NpO}_{2}$ samples at high gamma dose rates in order to measure gas generation rates and corresponding pressure changes as a function of moisture on the oxide particles. This will be done in the HFIR pool because the spent cores there are the only source of suitable high dose rate gamma irradiation capable of radiolyzing significant quantities of the proposed materials in a short time period.

Ten samples of $\mathrm{NpO}_{2}$ will be irradiated to evaluate radiolytic decomposition of water. The samples will first undergo chemical processing to prepare the $\mathrm{NpO}_{2}$ in a form similar to that expected from SRS. There are two main variables effecting gas generation. These are the water content of the material and the specific surface area per unit weight. The water content is important since water is believed to be radiolyzed to hydrogen and oxygen thus influencing the total hydrogen production possible. The specific surface area, in $\mathrm{m}^{2} / \mathrm{gm}$, determines how much water can be absorbed as monolayer and determines when sorption goes from monolayer sorption to multiple layers. Some researchers believe that the surface may catalyze certain chemical reactions thus impacting gas generation. Both of these effects will be studied in these experiments.

To prepare $\mathrm{NpO}_{2}$ for these experiments, a batch of 80-100 gm of $\mathrm{NpO}_{2}$ was dissolved in nitric acid. The valence of neptunium was adjusted to the +4 valence state. A slight excess of oxalic acid was added to precipitate neptunium oxalate. The resulting material was filtered, dried, and fired to $650 \mathrm{EC}$ to convert the oxalate to oxide. After cooling, 
a portion of the oxide was removed and fired at $800 \mathrm{EC}$. The temperature of $650 \mathrm{EC}$ was chosen based on the SRS flowsheet. The second temperature of $800 \mathrm{EC}$ was chosen to give a change in surface area. Similar oxalate products made with plutonium showed a decrease in surface area from $\sim 14 \mathrm{~m}^{2} / \mathrm{gm}$ for material fired at $650 \mathrm{EC}$ to $\sim 6 \mathrm{~m}^{2} / \mathrm{gm}$ for material fired at $800 \mathrm{EC}$.

The $\mathrm{NpO}_{2}$ for these experiments was analyzed and results are given in Tables 1 and 2. Table 1 provides isotopic information while Table 2 presents chemical impurity information.

The irradiation sample tubes for HFIR are shown in Fig. 1 along with the irradiation vessel that hold the tubes.

The adsorption water onto neptunium oxide has been studied to determine appropriate water content of the samples. Figure 2 shows the uptake of water by $\mathrm{NpO}_{2}$ as can be seen from the figure, the overall uptake is about $8 \%$ and requires about 90 days to plateau.

Neptunium oxide with varying amounts of sorbed water will be prepared by placing these materials in a controlledhumidity environment. A portion of the material will be separated for low dose rate irradiation studies in the Co-60 irradiator located in Building 4501. These studies are expected to run concurrently with the HFIR SNF irradiation studies and provide evidence that $\mathrm{NpO}_{2}$ behaves in a manner similar to uranium oxides. Additional samples will be prepared with ${ }^{244} \mathrm{Cm}$ added to examine the effects of alpha radiolysis during the long term storage.

Table 1. Neptunium Isotopic Data

\begin{tabular}{ll}
\hline & Isotopic abundance \\
\hline${ }^{237} \mathrm{~Np}$ & 99.97361 \\
${ }^{239 / 240} \mathrm{Pu}$ & 0.02558 \\
& 0.0008 \\
\hline
\end{tabular}

Current effort focused on getting approval of safety documents for the HFIR irradiation.

\subsubsection{Neptunium Transfer from SRS Support Studies}

Transfer of $\mathrm{NpO}_{2}$ from SRS to ORNL will require close coordination with SRS staff. Several transportation packages were identified during the FY01 work. Current plans are to meet at SRS early in the next quarter to begin detailed planning for the $\mathrm{NpO}_{2}$ transfer.

\section{References}

1. A. S. Icenhour Radiolytic Effects on Fluoride Impurities in a $\mathrm{U}_{3} \mathrm{O}_{8}$ Matrix, ORNL/TM-2000/157, May 2000.

2. A. S. Icenhour, L. M. Toth, Gamma Radiolysis Study of $\mathrm{UO}_{2} \mathrm{~F}_{2} @ 4 \mathrm{H}_{2} \mathrm{O}$ Using Spent Nuclear Fuel Elements from the High Flux Isotope Reactor, ORNL/TM-2001/138.

3. A. S. Icenhour, L. M. Toth, H. Luo, Water Sorption and Gamma Radiolysis Studies for Uranium Oxides, $\underline{\text { ORNL/TM }} \underline{-2001 / 59}$. 
Table 2. Chemical Analysis of $\mathrm{NpO}_{2}$ Samples

\begin{tabular}{|c|c|}
\hline & $\begin{array}{c}\text { Concentration } \\
\text { Dilution corrected results } \\
(\mathrm{Fg} / \mathrm{g})\end{array}$ \\
\hline $\mathrm{Ag}$ & $<3.61 \mathrm{E}+02$ \\
\hline $\mathrm{Al}$ & $1.38 \mathrm{E}+04+/-1.38 \mathrm{E}+03$ \\
\hline B & $9.19 \mathrm{E}+03+/-9.19 \mathrm{E}+02$ \\
\hline $\mathrm{Ba}$ & $6.03 \mathrm{E}+03+/-6.03 \mathrm{E}+02$ \\
\hline $\mathrm{Be}$ & $4.25 \mathrm{E}+01+/-4.25 \mathrm{E}+00$ \\
\hline $\mathrm{Ca}$ & $1.94 \mathrm{E}+04+/-1.91 \mathrm{E}+03$ \\
\hline $\mathrm{Cd}$ & $<3.44 \mathrm{E}+03$ \\
\hline Co & $<2.12 \mathrm{E}+03$ \\
\hline $\mathrm{Cr}$ & $<4.46 \mathrm{E}+02$ \\
\hline $\mathrm{Cu}$ & $6.79 \mathrm{E}+02+/-8.49 \mathrm{E}+01$ \\
\hline $\mathrm{Fe}$ & $6.52 \mathrm{E}+03+/-1.36 \mathrm{E}+03$ \\
\hline K & $8.43 \mathrm{E}+03+/-2.08 \mathrm{E}+03$ \\
\hline $\mathrm{Mg}$ & $1.41 \mathrm{E}+04+/-1.31 \mathrm{E}+03$ \\
\hline $\mathrm{Mn}$ & $2.34 \mathrm{E}+02+/-4.25 \mathrm{E}+01$ \\
\hline Mo & $<1.10 \mathrm{E}+03$ \\
\hline $\mathrm{Na}$ & $5.44 \mathrm{E}+04+/-5.44+03$ \\
\hline $\mathrm{Ni}$ & $<1.06 \mathrm{E}+03$ \\
\hline $\mathrm{Sb}$ & $3.27 \mathrm{E}+03+/-7.22 \mathrm{E}+02$ \\
\hline $\mathrm{Sr}$ & $3.40 \mathrm{E}+02+/-3.40 \mathrm{E}+01$ \\
\hline Th & $<5.33 \mathrm{E}+03$ \\
\hline $\mathrm{Tl}$ & $<2.55 \mathrm{E}+02$ \\
\hline $\mathrm{U}$ & $<7.20 \mathrm{E}+03$ \\
\hline V & $<1.32 \mathrm{E}+03$ \\
\hline $\mathrm{Zn}$ & $<1.22 \mathrm{E}+04$ \\
\hline $\mathrm{Zr}$ & $<1.49 \mathrm{E}+02$ \\
\hline
\end{tabular}




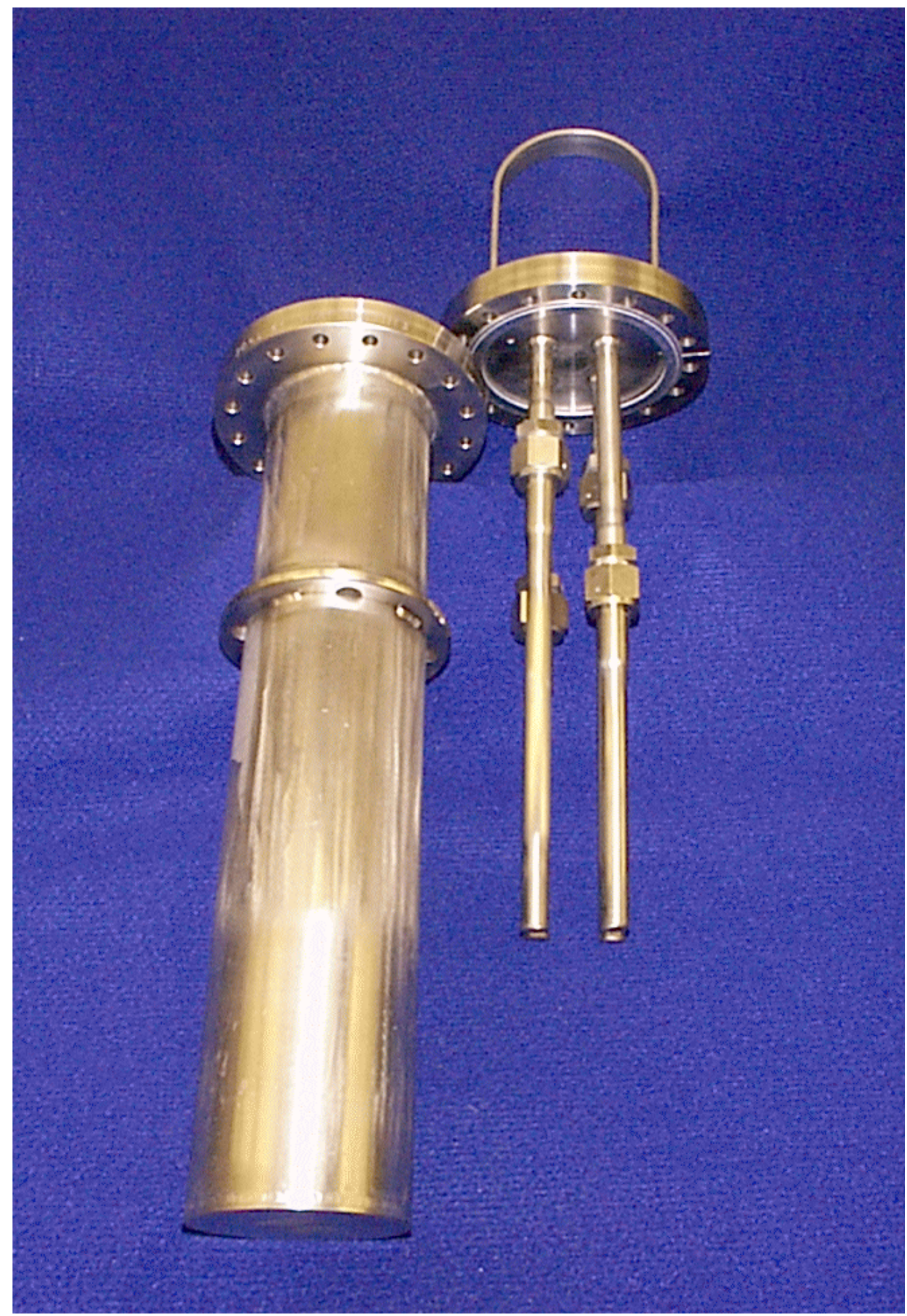

Figure 1. Sample tubes for gamma irradiation of neptunium oxide. 


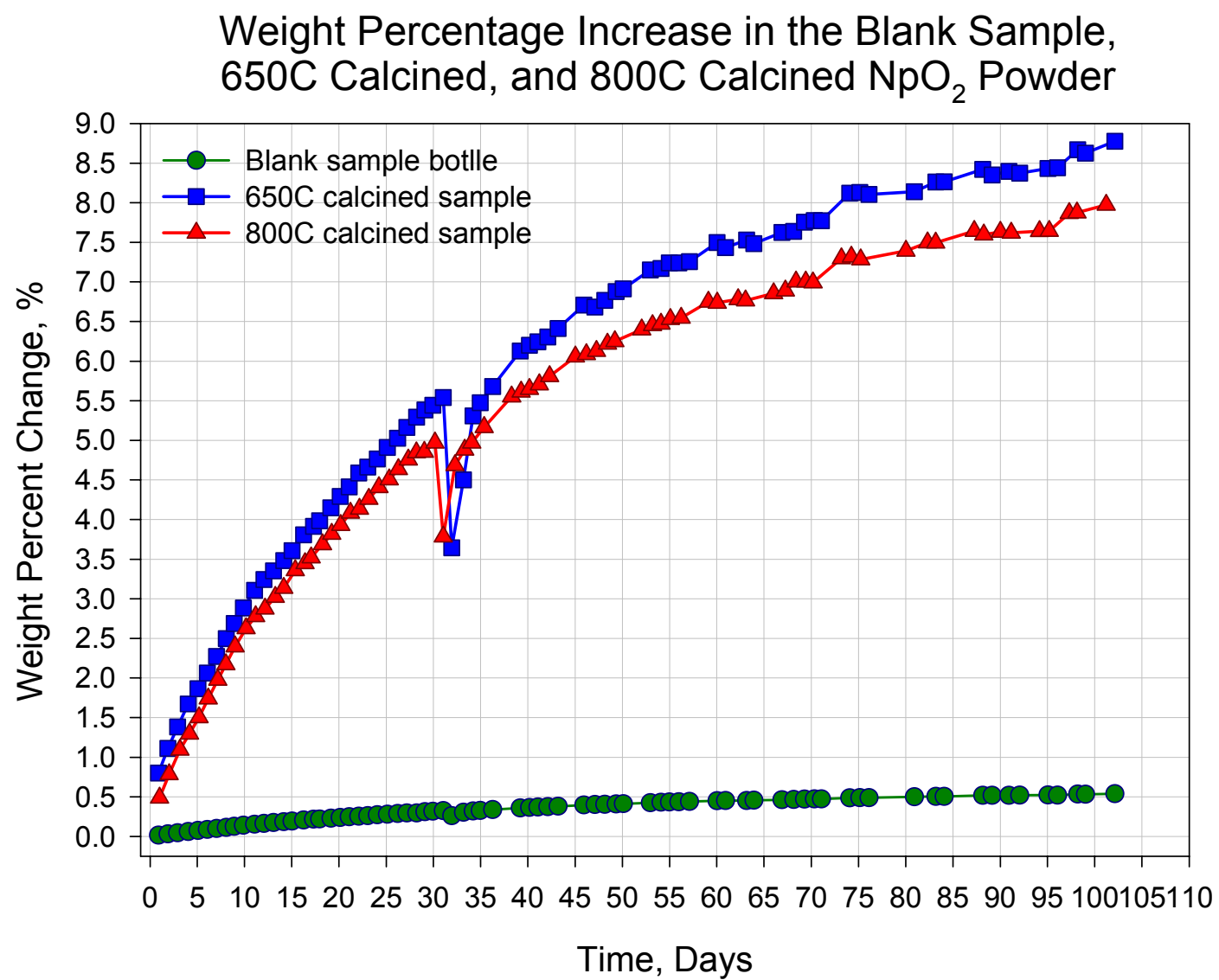

Figure 2. Weight percentage increases in the blank sample, $650 \mathrm{EC}$ calcined, and $800 \mathrm{EC}$ calcined $\mathrm{NpO}^{2}$ powder during Co-60 irradiaiton.

Table 3. Expected Characteristics of $\mathrm{NpO}_{2}$ Gas Generation

\begin{tabular}{lccc}
\hline & $\begin{array}{c}\text { Wt of } \mathrm{NpO}_{2} \\
(\mathrm{~g})\end{array}$ & $\mathrm{Wt} \%$ water & Firing temp (EC) \\
\hline HFIR-GI-Np-1-1 & 4 & $<1$ & 650 \\
HFIR-GI-Np-1-2 & 4 & 1 & 650 \\
HFIR-GI-Np-1-3 & 4 & 10 & 650 \\
HFIR-GI-Np-1-4 & 4 & $1-10$ & 800 \\
Co-60-GI-Np-1-1 & 4 & $<1$ & 650 \\
Co-60-GI-Np-1-2 Co- & 4 & 1 & 650 \\
60-GI-Np-1-3 & 4 & 10 & 650 \\
Co-60-GI-Np-1-4 & 4 & $1-10$ & 800 \\
& & & \\
Cm-AR-Np-1-1 & 2 & $<1$ & 650 \\
Cm-AR-Np-1-2 Cm- & 2 & 1 & 650 \\
AR-Np-1-3 & 2 & 10 & 650 \\
Cm-AR-Np-1-4 & 2 & $1-10$ & 800 \\
& & & \\
& & & \\
\hline
\end{tabular}




\section{INTERNAL DISTRIBUTION}

1. E. P. George

2. J. S. Ivey

3. J. F. King

4. C. G. McKamey

5-7. J. P. Moore

8. E. K. Ohriner
9. G. R. Romanoski

10. G. B. Ulrich

11. M. C. Vance

12. R. M. Wham

13. Laboratory Records

\section{EXTERNAL DISTRIBUTION}

14-22. U. S. DEPARTMENT OF ENERGY, NE-50, Germantown Building, 11901 Germantown Road, Germantown, MD 20874-1290
C. E. Brown
R. C. Raczynski
J. Dowicki
L. L. Rutger
R. R. Furlong
E. J. Wahlquist
L. C. Herrera
R. L. Wiley
A. S. Mehner

23. DEPARTMENT OF ENERGY, Albuquerque Field Office, P.O. Box 5400, Albuquerque, NM 87115 R. L. Holton

24-25. DEPARTMENT OF ENERGY, Oak Ridge Operations Office, Bldg. 4500N, Oak Ridge, TN 37831

L. W. Boyd, Mail Stop 6390

S. R. Martin, Jr., Mail Stop 6269

26. DEPARTMENT OF ENERGY, Los Alamos Area Office, 528 35th Street, Los Alamos, NM 87544

R. J. Valdez

27. DEPARTMENT OF ENERGY, Savannah River Operations Office, Bldg. 703F, P.O. Box A, Aiken, SC 29802

S. W. McAlhaney

28. DEPARTMENT OF ENERGY, Miamisburg Office, P.O. Box 66, Miamisburg, OH 45342

T. A. Frazier

29. BABCOCK AND WILCOX OF OHIO, INC., 1 Mound Road, Miamisburg, OH 45343-3000

D. M. Gabriel

30. LOCKHEED MARTIN ASTRONAUTICS, P.O. Box 8555, Philadelphia, PA 19101

R. M. Reinstrom 
31. LOS ALAMOS NATIONAL LABORATORY, P.O. Box 1663, NMT-9, MS E502, Los Alamos, NM 87545

E. M. Foltyn

32. TETRA TECH NUS INC., 910 Clopper Road, Suite 400 Gaithersburg, MD 20878-1399

B. W. Bartram

33-34. ORBITAL SCIENCES CORPORATION, INC., 20030 Century Blvd., Suite 102, Germantown, MD 20874

R. T. Carpenter

E. A. Skrabek

35. PHILLIPS LABORATORY, Kirtland Air Force Base, AFRL/VSDV, 3550 Aberdeen Avenue SE, NM 87117

C. Mayberry

36. TELEDYNE BROWN ENGINEERING-ENERGY SYSTEMS, 10707 Gilroy Road, Hunt Valley, Maryland 21031

M. F. McKittrick

37. TEXAS A\&M UNIVERSITY, Center for Space Power, Mail Stop 3118, College Station, TX 77843

M. J. Schuller

38. WESTINGHOUSE ADVANCED TECHNOLOGY BUSINESS AREA, P.O. Box 355, Pittsburgh, PA 15230-0355

M. O. Smith

39. WESTINGHOUSE SAVANNAH RIVER COMPANY, Savannah River Site, Aiken, SC 29808

R. W. Saylor 